\title{
Effect of alkalinity and calcium concentration of pore solution on the swelling and ionic exchange of superabsorbent polymers in cement paste
}

\author{
H. X. D. Lee, H. S. Wong* and N. R. Buenfeld \\ Concrete Durability Group, Department of Civil and Environmental Engineering, Imperial College London, UK
}

\begin{abstract}
Swelling kinetics of superabsorbent polymers (SAP) in fresh concrete is complex, but its understanding is crucial for optimisation in practical applications. In this study, the effect of concentration of ions common in pore solution $\left(\mathrm{Na}^{+}, \mathrm{K}^{+}, \mathrm{Ca}^{2+}, \mathrm{Cl}^{-}, \mathrm{OH}^{-}, \mathrm{SO}_{4}^{2-}\right)$ and cyclic wetting/drying on the swelling and ionic exchange of poly(AA) and poly(AA-co-AM) were investigated. Results show that swelling is not a simple function of concentration or ionic strength. In cement paste, SAP absorbs $\mathrm{Ca}^{2+}$ and releases its counterion $\left(\mathrm{Na}^{+}, \mathrm{K}^{+}\right)$into pore solution. $\mathrm{Ca}^{2+}$ binds with SAP and decreases initial swelling, but the bound $\mathrm{Ca}^{2+}$ can be displaced and swelling gradually recovers. Swelling increases with increase in alkalinity, but decreases with increase in calcium concentration. The higher the degree of ion exchange, the lower the swelling of SAP. Poly(AA) is more susceptible to $\mathrm{Ca}^{2+}$ complexation and therefore achieves a lower swelling ratio and slower swelling recovery compared to poly(AA-co-AM).
\end{abstract}

Keywords: Superabsorbent polymer; Swelling; Pore solution; Crack sealing; Internal curing, Durability

\section{Introduction}

There has been much interest in recent years on the potential use of superabsorbent polymers (SAP) in concrete. Superabsorbent polymers are cross-linked polymers that have the ability to absorb a disproportionately large amount of water relative to their own mass and expand to form an insoluble gel. SAPs are a subset of a large family of hydrogels and polyelectrolytes polymer gels [1]. The majority of commercially available SAP are anionic gels comprised of cross-linked acrylic acid that is partially neutralised with sodium hydroxide. These are referred to as polyacrylate (poly(AA)) and they contain partially neutralised carboxylate functional groups with the counterions typically being hydrogen, sodium and potassium. Other monomers are also used such as acrylamide to produce poly(acrylate-co-acrylamide) (poly(AA-co-AM)). The acrylamide group is non-ionic, while the carboxylate group is anionic in water due to partial dissociation of the counterions. Poly(AA) and poly (AA-co-AM) are also the most commonly used SAP in cement-based materials.

\footnotetext{
* Corresponding author. E-mail: hong.wong@imperial.ac.uk. Tel: +44 (0)20 75945956
} 
The key properties of SAP is their ability to absorb and retain water, during which the swollen gel forms a barrier to flow, and to release the absorbed water when the surrounding humidity drops. The main application of SAP is in personal hygiene products (diapers). Other uses include biomedical (bandages, tissue engineering, implants), pharmaceutical (drug delivery), agricultural (soil conditioning), waste treatment/separation, meat packaging and water blocking tapes for undersea cables [1,2]. Several potential applications of SAP in concrete have been suggested. These include its use as an internal curing agent to reduce self-desiccation and autogenous shrinkage in low water/cement mixtures [3-5], rheology control, frost protection [6, 7] and crack sealing/healing [8-15]. A state-of-the-art report on the application of superabsorbent polymers in concrete was published by RILEM in 2012 [16].

A detailed description of the swelling mechanism of SAP is available elsewhere, e.g. Tanaka et al. [17], Ricka \& Tanaka [18], Hooper et al. [19], Buchholz \& Graham [1] and Gedde [20]. In essence, when $\mathrm{SAP}$ is exposed to an aqueous solution, a transition in chemical potential occurs between the gel and solution leading to swelling or shrinkage of the SAP. The main driving force for swelling is osmotic pressure arising from the difference in the concentration of ions between the gel and solution. This is balanced by the elastic forces arising from deformation of the polymer chains that restrain swelling. The amount of deformation depends on the elastic modulus of the gel, which in turn depends on its cross-link density. SAP also deswells under compression by reverse osmosis. Equilibrium is achieved when these potentials are equalised and the net swelling pressure becomes zero. As such, the amount and kinetics of SAP swelling depends on the properties of the polymer such as ionic groups, degree of cross-linking and particle size as well as the properties of the solution such as type of ions present, concentration, ionic strength, $\mathrm{pH}$, pressure and temperature [1, 21-25] . For example, the mass of water absorbed per mass of SAP, known as the swelling ratio or absorption capacity, can be as high as $500 \mathrm{~g} / \mathrm{g}$ in distilled water, but reduces to $\sim 50 \mathrm{~g} / \mathrm{g}$ in dilute salt solution and $\sim 10 \mathrm{~g} / \mathrm{g}$ in concrete pore solution.

Swelling of SAP in cement-based materials is a complex phenomenon. This is because the pore solution of cement-based materials consists of multi-species (mainly $\mathrm{Na}^{+}, \mathrm{K}^{+}, \mathrm{Ca}^{2+}, \mathrm{OH}^{-}$and $\mathrm{SO}_{4}{ }^{2-}$ ) and the concentration of each species varies with cement type, mixture composition. Furthermore, the composition of pore solution varies over time due to hydration (dissolution of cement, precipitation of hydration products) and interactions with the exposure environment (wetting/drying, ingress of external fluids, leaching etc). Understanding the factors influencing swelling and shrinkage of SAP in cement-based materials is essential in order to optimise its usage as well as to understand its long-term effects in concrete. For example, the swelling kinetics of SAP in fresh concrete is important because it influences mixture design, the amount of entrained water and SAP dosage required for a particular application, rheology and workability [26]. The ionic groups of the SAP affect when the absorbed water is released for internal curing application [23, 27], how ingress of external fluids influence its re-swelling in crack sealing [13] and how repeated swelling/shrinkage influences long-term performance. The swelling of SAP changes the microstructure (void content) of hardened concrete; this in turn can have a great impact on strength and long-term durability. 
This study aims to investigate the effects of alkalinity and calcium content in the pore solution on the swelling of poly(AA) and poly (AA-co-AM) SAP in cement paste. Furthermore, the study will investigate the effects of SAP type and dosage on the composition of pore solution extracted from cement paste, to establish the ion exchange that may occur between SAP and pore solution, and how this influences swelling. Swelling ratio of SAP was first measured in various simple aqueous solutions and synthetic pore solutions to investigate the effects of ion type $\left(\mathrm{Na}^{+}, \mathrm{K}^{+}, \mathrm{Ca}^{2+}, \mathrm{Cl}^{-}, \mathrm{OH}^{-}, \mathrm{SO}_{4}{ }^{2-}, \mathrm{NO}_{3}{ }^{-}\right)$and concentration, ionic strength and repeated wetting/drying. Then, a range of cement pastes with various levels of alkalinity, calcium content and SAP dosage were prepared and tested. Pore solution was extracted and analysed using ICP-OES and the swelling of SAP in hardened cement paste was measured using image analysis. Finally, energy dispersive Xray microanalysis was used to map element distribution in the SAP and surrounding cement paste. It is hoped that the findings from this study will help in optimisation and enhancing the effectiveness of SAP in concrete applications.

\section{Experimental}

\subsection{Materials}

The cements used in this study were white Portland cement (WPC, $52.5 \mathrm{~N}$ ) and ordinary grey Portland cement (CEM I, 52.5N) complying with BS EN 197-1 from Lafarge. White Portland cement was used in addition to grey Portland cement because of its low alkalinity. The oxide compositions and other properties of the cements are shown in Table 1. Two types of SAPs were investigated: crosslinked polyacrylic acid neutralised with sodium hydroxide and crosslinked copolymer of acrylic acid and acrylamide, neutralised with potassium hydroxide. These will be referred to as polyacrylate (poly AA) and polyacrylate-coacrylamide (poly AA-co-AM), designated as S2 and S5 respectively so as to be consistent with our previous publications [10,13]. S2 has relatively higher degree of cross-linking and density of anionic groups compared to S5. Their particle sizes are in the range of 100-300 $\mu \mathrm{m}$ and 1-200 $\mu \mathrm{m}$ for S2 and S5 respectively. The SAPs are synthesised from bulk polymerisation and subsequently ground into small particles. When viewed using an optical microscope in transmitted light and scanning electron microscope, the SAPs appear as smooth, angular shaped granules with a small amount of convoluted sheets. This is a result of the grinding process after solution polymerization in their manufacture. Fig. 1 shows scanning electron micrographs highlighting the particle size, surface texture and particle shape of the SAPs.

The properties of the SAPs including their swelling ratios in deionised water, $0.12 \mathrm{wt} . \% \mathrm{NaCl}$, synthetic shallow groundwater and synthetic pore solution are shown in Table 2 . The composition of synthetic groundwater was based on a relatively concentrated groundwater with ionic strength of $21 \mathrm{mmol} / \mathrm{L}$ [28], in mmol/L: $\mathrm{NaHCO}_{3}$ (8.2), $\mathrm{CaSO}_{4}$ (1.04), $\mathrm{MgSO}_{4}$ (2.08) and $\mathrm{CaCl}_{2}$ (0.14). The composition of synthetic pore solution (PS1) was based on pore solution extracted from a $0.5 \mathrm{w} / \mathrm{c}$ ratio cement paste (ordinary grey Portland cement) within 30 minutes of mixing [29], in mmol/L: $\mathrm{CaSO}_{4}(20.6), \mathrm{K}_{2} \mathrm{SO}_{4}(163.4$ ), 
$\mathrm{KOH}$ (71.2) and $\mathrm{NaOH}$ (73.9). The SAP (S5) was sieved to remove a small fraction of particles smaller than $75 \mu \mathrm{m}$. This was done to ensure that the SAP voids in hardened cement paste can be imaged with a flatbed scanner so that the SAP swelling in cement paste can be accurately measured with image analysis (see Section 2.4).

\subsection{Mixtures}

Forty one cement paste mixtures were prepared at water-to-cement ratio of 0.6. These are divided into six series, and the details of the mixtures are summarised in Table 3. Cement paste rather than mortars or concretes were prepared in this study for the sake of convenience and simplicity. The presence of aggregates is not expected to have a significant influence on pore solution composition, therefore the findings from this study should also be applicable to mortars or concretes. A relatively high w/c ratio was used to facilitate expression of pore solution for the work described in Section 2.5. Series I and II were prepared with the aim of understanding the influence of alkali and calcium content on the absorption capacity of SAP in cement paste. Series III to VI were prepared to investigate the effect of SAP on the composition of pore solution. In Series I and V, a measured amount of sodium hydroxide was dissolved in the batch water to produce samples with total equivalent $\mathrm{Na}_{2} \mathrm{O}$ content ranging from $0.09 \%$ to $0.9 \%$ wt. cement. In Series II and VI, calcium nitrate was added to the batch water to increase the calcium concentration of the pore solution. The amount of calcium nitrate added ranged from $0.5 \%$ to $4 \%$ wt. cement.

Dosage of SAP was either $0.6 \%$ or $2 \%$ by weight of cement. The relatively high SAP dosage of $2 \%$ wt. cement was used because these samples were prepared as part of a study on the feasibility of SAP as an admixture for self-sealing cracks in concrete [12]. Deionised water was used as batch water in all cases. Additional water was added to mixtures with SAP to account for the amount absorbed by the SAP so that the target free w/c ratio was achieved. This was determined by conducting many trial mixtures to measure the additional water required to obtain a mixture with similar consistency to the control mixture. Consistency was judged by comparing the spread of the freshly prepared mixture on a flow table. This method assumes that the SAP itself does not significantly influence the rheology of the cement paste.

Batching was carried out by dry mixing cement with the required amount of SAP for 2 minutes. Batch water was then added and mixed for 15 minutes. An extended mixing time was used to ensure homogeneity and to allow the SAP swelling to stabilise before casting. Samples were cast in plastic cylindrical containers $(50 \emptyset \times 60 \mathrm{~mm})$ and compacted in three equal layers by gentle tapping to remove entrapped air. Each compacted sample was capped with a plastic lid, sealed with water-resistant tape, and continuously rotated for the first 48 hours to prevent segregation. Samples were then sealed cured by wrapping in a generous amount of cling film, then placed in sealed polythene bags and cured in $\mathrm{CO}_{2}$ free environment at $20^{\circ} \mathrm{C}$ for a further 7 days. 


\subsection{Swelling and repeated swelling of SAP in test solutions}

Swelling ratio of SAP in aqueous solution was measured using suction filtration [30]. In this method, $100 \mathrm{mg}$ of SAP pre-dried at $50^{\circ} \mathrm{C}$ (to constant mass) was added to a beaker containing $100 \mathrm{~mL}$ of the test solution, which was then sealed and left for $24-30$ hours at $20^{\circ} \mathrm{C}$. The swollen SAP was then filtered by suction at 0.17 bar over a pre-saturated filter paper (Waterman No.1) for 5 minutes. The filtered SAP and the wet filter paper were then immediately transferred into a polystyrene weighing boat and weighed. Swelling ratio $(s)$ was calculated from the following equation:

$$
s=\frac{\left(w_{2}-w_{3}\right)-w_{1}}{w_{1}}
$$

Where $w_{1}$ is the initial mass of the pre-dried SAP, $w_{2}$ is the mass of the swollen SAP and wet filter paper, and $w_{3}$ is the mass of the wet filter paper obtained from a control experiment with no SAP. Repeated measurements ( 5 replicates) were carried out for both SAPs and the standard deviation was less than $3 \%$ in all cases. The variability within replicates is small compared to the effect of the imposed experimental parameters on swelling ratio.

It should be noted that there exist a number of methods for measuring SAP swelling ratio. The most commonly used is the gravimetric "tea-bag" method, for example as described in [31]. In this study, vacuum filtration with a small negative pressure was adopted rather than the tea-bag method because it has the advantage of removing physically held capillary water between SAP particles. However, it is possible that the small negative pressure may not completely remove all inter-particle water. Nevertheless, this does not matter to the current study as long as the same consistent method is used throughout.

In the first set of experiments, the swelling of SAP was measured after exposure to two synthetic pore solutions, PS1 and PS2. PS1 is the same as the synthetic pore solution described in Section 2.1 and is relatively concentrated ('strong'). PS2 is a relatively less concentrated ('weak') pore solution containing the following in mmol/L: $\mathrm{CaSO}_{4}$ (15.7), $\mathrm{KOH}$ (20.4), $\mathrm{NaOH}(5.3)$ and $\mathrm{Ca}(\mathrm{OH})_{2}$ (4) [29]. The swelling ratio was measured after various periods of exposure to study the absorption kinetics in synthetic pore solution. The exposure time steps were $\sim 5,10,30,60,120,240,480$ and 1000 minutes.

In the second set of experiments, the swelling of SAP was measured in various salt solutions to examine the influence of anion/cation type, concentration and ionic strength. The solutions were $\mathrm{KCl}, \mathrm{NaCl}$, $\mathrm{CaCl}_{2}, \mathrm{NaOH}$ and $\mathrm{Na}_{2} \mathrm{SO}_{4}$ at the following concentrations: 1, 2, 5, 10, 20, 50, 100, 200 and $500 \mathrm{mmol} / \mathrm{L}$. Swelling ratio was also measured in solutions containing $20 \mathrm{mmol} / \mathrm{L} \mathrm{CaCl}_{2}$ with increasing amount of $\mathrm{NaCl}$ at 10, 20, 50, 100, 200, 400, 600, 800, 1000 and $1200 \mathrm{mmol} / \mathrm{L}$. In these measurements, the SAP was left in the beaker for 24-30 hours to allow swelling to reach equilibrium.

In the third set of experiments, the same SAP sample was tested repeatedly to examine the effect of wetting and drying cycles on swelling behaviour. After the first measurement, the swollen SAP was removed 
from the filter paper and oven-dried at $50^{\circ} \mathrm{C}$ until constant mass. The dried SAP was then weighed and added to a beaker containing fresh test solution to determine the amount of absorption in the second cycle. This was repeated following the regimes shown in Table 4. The solutions used in regimes A, B and C were either $\mathrm{NaCl}$ or $\mathrm{CaCl}_{2}$ to simulate groundwater at different concentrations. Regime $\mathrm{D}$ was used to study the combined effects of monovalent and divalent cations $\left(\mathrm{Na}^{+}, \mathrm{Ca}^{2+}\right)$ on repeated swelling. Regimes $\mathrm{E}, \mathrm{F}$ and $\mathrm{G}$ were used to simulate re-swelling of SAP in groundwater following an initial swelling in a relatively concentrated calcium bearing solution. Around 10-20\% of the SAP was 'lost' to the filter paper at each cycle. Therefore, the amount of solution used in the subsequent cycle was adjusted accordingly to maintain a constant mass ratio of test solution to SAP at 500:1. $400 \mathrm{mg}$ of SAP was used at the start to ensure a sufficient amount remaining throughout the entire experiment.

\subsection{Swelling of SAP in cement paste}

The swelling ratio of SAP in cement paste was determined using image analysis by measuring the volume fraction of the SAP and its macro-inclusions, i.e. the voids that are produced when cast-in SAP dries and shrinks in the hardened cement paste [32]. According to stereology [33, 34], the volume fraction of particular phase in a multi-phase material equals its area fraction measured on a random plane through the material. This random plane was produced by sectioning each cement paste sample with a diamond abrasive cutter to produce three blocks of $50 \times 25 \times 15 \mathrm{~mm}$ along the length of the cylinder. The top and bottom surfaces of each block were flat ground with silicon carbide paper at $70 \mathrm{rpm}$ and at gradually increasing fineness, starting from a coarse grit of 120 down to 220, 600 and 1000 grit, for 2 minutes at each step. At the end of each grinding step, the blocks were cleaned with paper towel followed by acetone in a sonication bath for 1 minute to dislodge and remove debris from the SAP voids. The grinding process removed approximately $1 \mathrm{~mm}$ from the top and the bottom surfaces of each block.

A significant amount of SAP particles remained on the surface and these must be removed to enable accurate measurement of swelling ratio with image analysis. Several means for achieving this were trialled including wetting and oven drying $\left(105^{\circ} \mathrm{C}\right)$, and sonication in various solvents (acetone, toluene and sodium chloride) to agitate the SAP particles followed by oven drying. It was found that the most effective approach was by heating the blocks at $600^{\circ} \mathrm{C}$ for an hour, and then cooling gradually to room temperature followed by sonication in acetone to release the SAP particles. At such high heating rate, it is unlikely that the SAP would form a liquid substance that diffuses into the cement paste matrix. In any case, this does not influence the measured swelling ratio. Visual inspection found that cracking was avoided by heating and cooling gradually and by using thin blocks.

Subsequently, the blocks were surface treated to enhance the contrast between the hardened cement paste and SAP voids to facilitate image analysis. This was done by colouring the surface with a black permanent marker pen in two coatings, each coat applied perpendicular to the other. Then, white talcum powder (particle size $<10 \mu \mathrm{m}$ ) was spread on the dry coated surface and gently pressed into voids with a 
glass slide. Excess powder was swept off with the edge of a razor blade. The entire top and bottom surfaces of each block were then imaged with a flatbed scanner at 2,400 dpi, achieving a pixel size $10.6 \mu \mathrm{m}$, which is sufficient to resolve the SAP voids. Six scans were collected per mixture and the total surface area analysed was $125 \mathrm{~cm}^{2}$. The total number of individual SAP particles measured per sample was more than 1000 . Prior to imaging, trials were carried out to determine the optimum contrast and brightness settings of the scanner to achieve a broad image brightness histogram. This ensures that the entire dynamic range of available greyscale is utilised to achieve the best possible contrast. The same scanner settings were applied for all samples for consistency. Visual inspection of the scanned images found no significant amount of preparation damage (e.g. cracks) that would otherwise influence results.

Image analysis and processing were performed using AnalySIS (Soft Imaging System GmbH). Fig. 2a shows a magnified portion from a scanned image of surface-treated cement paste containing SAP. It can be seen that the voids are highly contrasted from the cement paste. The brightness histogram (Fig. 2c) shows a bi-modal distribution. The peak to the right of the histogram represents voids that have been filled with the white talcum powder and the peak to the left represents cement paste that has been coated with black ink. The grey value at midpoint between the two peaks was selected as the threshold value to segment the voids. It should be noted that this method produced very consistent threshold values $(\sim 120)$ for all images and this is attributable to the surface treatment to enhance void contrast and also to the care in imaging using consistent settings.

Fig. $2 \mathrm{~b}$ shows an example of the resulting binary image of the segmented voids. The area fraction of the segmented voids represents the sum of the SAP voids $\left(F_{S V}\right)$, SAP particles $\left(F_{S A P}\right)$ and any entrapped air $\left(F_{A V}\right)$. However, SAP voids may appear spherical and so distinguishing them from entrapped air in the binary image becomes problematic. To overcome this, a control cement paste (no SAP) at the same w/c ratio was prepared and surface treated in the same manner, and analysed. The measured void fraction in the control represents the volume fraction of entrapped air $\left(F_{A V}\right)$ and this was assumed to be the same as that in samples containing SAP. Therefore, the swelling ratio of the SAP can be calculated using the following equation as derived in Lee et al. [32]:

$$
s=\frac{F_{S v+S A P} \rho_{a s}}{m_{S A P} \rho}-\frac{\rho_{a s}}{\rho_{S A P}}
$$

Where $m_{S A P}$ is the mass fraction of SAP to the sample, and $\rho, \rho_{a s}$ and $\rho_{S A P}$ are the densities of the sample (measured), absorbed solution $\left(1 \mathrm{~g} / \mathrm{cm}^{3}\right)$ and SAP $\left(1.66 \mathrm{~g} / \mathrm{cm}^{3}\right)$. This equation assumes that the volume of the measured SAP voids is equal to the volume of the absorbed solution.

\subsection{Pore solution composition}

The ion exchange, specifically the uptake of calcium and the release of sodium and potassium by the SAP, was studied by measuring the change in concentration of pore solution extracted from cement pastes with and without SAP. Pore solutions were extracted from freshly mixed cement pastes from Series III to VI 
(Table 3) and immediately analysed using inductively coupled plasma optical emission spectrometer (ICPOES, PerkinElmer, Optima 7300DV) to measure elemental composition. The pastes were prepared in plastic containers and sealed to avoid carbonation as described in Section 2.2. The pore solutions were extracted and analysed at various periods between 40 and 500 minutes from the start of mixing. To extract the pore solution, about 40-80 g of the cement paste was transferred to a test tube and centrifuged at 10,000 rpm for 5 minutes. Trials with only the swollen SAP found that this procedure did not remove significant amount of the absorbed solution. The extracted pore solution from cement paste was then injected through a PES syringe filter $(0.22 \mu \mathrm{m}$ millipore) to remove any residual solids. The syringe filter was tested using various standard solutions to confirm its compatibility with the pore solution. $1 \mathrm{ml}$ of the extracted pore solution was diluted with $1 \mathrm{M} \mathrm{HCl}$ at a dilution factor of 200 , and $5 \mathrm{ml}$ of the diluted solution was then used for elemental analysis.

The concentration of $\mathrm{OH}^{-}$was determined by acid-base titration. About 0.5 to $2 \mathrm{ml}$ of the extracted pore solution was first diluted with deionised water at a dilution factor of 20 . Then, $5 \mathrm{ml}$ of the diluted solution was titrated against $0.01 \mathrm{M} \mathrm{HCl}$ using phenolphthalein as an indicator. The concentration of $\mathrm{OH}^{-}$can also be calculated by assuming electrostatic balance between the cations and anions and that the concentration of total sulfur is the same as that of sulfate in the solution. Comparison between the two results provides an indication of error in the experimental measurements.

\subsection{SEM-EDX analysis}

Scanning electron microscopy (SEM) in the backscattered electron (BSE) mode and energy dispersive $X$-ray (EDX) analysis were carried out to examine the microstructure of selected samples. In the first sample, dry SAP (S2) was mixed with CEM I and low-viscosity epoxy. The mixture was then cast into $40 \times 20 \times 10$ mm blocks, de-aired under vacuum and cured in air until the epoxy hardened. The second sample is a CEM I cement paste containing S2 that was cast into a similar block size and allowed to harden at room temperature. The paste was then oven-dried at $50^{\circ} \mathrm{C}$ and vacuum impregnated with a low viscosity fluorescent epoxy resin according to the procedure described in [35]. Both samples were then ground using silicon carbide papers of grit sizes 220,500 and 1200 , and diamond polished at $9,6,3,1$ and $1 / 4 \mu \mathrm{m}$. The polished surface was then gold coated and examined in high vacuum with a field-emission scanning electron microscope (Camscan Apollo 300) at $10 \mathrm{keV}$ beam energy.

EDX was carried out using Oxford Instruments INCA. An electron beam energy of $15 \mathrm{keV}$ was chosen as a compromise to achieve good spatial resolution, low X-ray absorption of the lighter elements, and to provide a sufficient overvoltage for heavier elements such as Fe. The beam current, measured with a Faraday cup, was maintained at $1.5 \mathrm{nA}$. This provided an acquisition rate of about $3 \mathrm{kcps}$ at $30 \%$ dead time, on all points measured. Beam dwell time was set at $100 \mu$ s and more than 250 frames were averaged to produce the element maps. Mapping was carried out at either $256 \times 208$ or $512 \times 416$ pixel resolution to approximately match the size of the X-ray sampling volume, which was determined via Monte-Carlo simulations [36]. 


\section{Results and discussion}

\subsection{Swelling in synthetic pore solutions}

Fig. 3 shows the changes in swelling ratio of SAP with time in synthetic pore solutions. Swelling of S5 (poly AA-co-AM) was consistently higher than S2 (poly AA) in all cases. Interestingly, both polymers achieved a higher swelling ratio in the 'strong' pore solution (PS1) compared to the 'weak' pore solution (PS2). This is surprising as one would expect the SAP to absorb less with increasing ionic concentration. We note that both pore solutions have similar concentration of $\mathrm{Ca}(\sim 20 \mathrm{mmol} / \mathrm{L})$, but PS1 has significantly higher amount of alkalis $([\mathrm{K}+\mathrm{Na}] \sim 470 \mathrm{mmol} / \mathrm{L})$ compared to PS2 $([\mathrm{K}+\mathrm{Na}] \sim 26 \mathrm{mmol} / \mathrm{L})$.

It can also be observed that most of the swelling for S5 (poly AA-co-AM) occurred within the first 10 minutes of mixing in both solutions. The liquid uptake increased only slightly beyond this and the swelling ratio achieved a relatively steady value after about 200 minutes in the pore solution. The swelling kinetics for S2 (poly AA) in the 'strong' pore solution (PS1) was similar to that for S5 and can be characterised by a fast absorption followed by a slight increase over time. However, its swelling kinetics in the weak pore solution (PS2) was very different. There was a fast absorption to $17 \mathrm{~g} / \mathrm{g}$ in the first 10 minutes, but this was followed by a gradual release of the absorbed water and the swelling ratio stabilised to approximately $3 \mathrm{~g} / \mathrm{g}$ beyond 120 minutes.

The observation above is consistent with Schroefl et al. [23, 27] who reported that polyacrylate SAP with high anionic functional group density swells very rapidly in pore solution, but releases most of the absorbed water over the first one to three hours. In contrast, polyacrylate-co-acrylamide SAP with lower anionic density is able to retain its absorbed water for much longer. However, our study also found that this behaviour is dependent on alkalinity. Essentially, a pore solution with higher alkalinity can decrease ion exchange and $\mathrm{Ca}^{2+}$ complexation, and so the SAP retains its swelling for a longer period. This explains why S2 behaved differently in PS1 compared to PS2. The higher swelling in the 'strong' pore solution (PS1) is because the higher concentration of monovalent cations in PS1 reduces the formation of swelling prohibiting bidentate complex by displacing the $\mathrm{Ca}^{2+}$ from the acrylate chain [37]. These effects will be shown and discussed in subsequent sections.

\subsection{Swelling in simple test solutions}

The effects of cation type, concentration and ionic strength on the swelling of poly(AA) and poly(AAco-AM) are shown in Fig. 4 and Fig. 5. Ionic strength (I) was calculated from the equation: $I=0.5 \sum c_{i} z_{i}{ }^{2}$, where $c_{i}$ and $z_{i}$ are the molar concentration $(\mathrm{mmol} / \mathrm{L})$ and charge number of ion $i$ in the solution respectively. The results demonstrate clearly that the swelling of SAP decreases with increase in concentration of the salt solution. It is interesting to note that for any particular concentration, the swelling of both SAPs in $\mathrm{NaCl}$ and $\mathrm{KCl}$ are of similar values, but significantly larger than that in $\mathrm{CaCl}_{2}$. This is consistent throughout the entire 
range of concentration tested from 1 to $500 \mathrm{mmol} / \mathrm{L}$ and it suggests that swelling behaviour is influenced by the valency of the cations in the test solution. When swelling ratio is plotted against ionic strength in Fig. 5, the disparity between absorbency in monovalent and bivalent cation decreases, but remains substantial.

The effects of anion type and concentration are shown in Fig. 6. The results also show that the swelling ratio of both SAP decreases with increasing concentration and ionic strength. Both SAPs achieved the lowest swelling ratio in $\mathrm{NaCl}$. However, the disparity between monovalent and bivalent anions is very small compared to the case for cations. This suggests that anion valency, at least for $\mathrm{Cl}^{-}, \mathrm{OH}^{-}$and $\mathrm{SO}_{4}{ }^{2-}$, has little influence on the swelling behaviour of SAP. Swelling ratio decreased by a factor of 10 in the range of concentration investigated for $\mathrm{Na}+, \mathrm{K}+, \mathrm{Cl}^{-}, \mathrm{OH}^{-}$and $\mathrm{SO}_{4}{ }^{2-}$. For $\mathrm{Ca}^{2+}$, a 100 times decrease in swelling ratio was observed.

Swelling of SAP decreases with increase in solution concentration because of the reduction in osmotic pressure that comes from the difference in ionic concentration between SAP and test solution. Furthermore, the dissolved ions screen repulsive forces between charged groups within the polymer. This charge screening effect reduces the driving force for swelling and so decreases absorption. However, the results also show that valency of the cations in the test solution has significant influence. Presence of multivalent cations such as $\mathrm{Ca}^{2+}$ produce a greater reduction in absorption compared to monovalent cations such as $\mathrm{Na}^{+}$and $\mathrm{K}^{+}$, and this observation is consistent with other studies, for example $[23,24,38,39]$. The is caused by the ability of $\mathrm{Ca}^{2+}$ to interact and bind with carboxylate groups from different acrylate chains in the polymer, forming additional cross-links that restrain the movement between acrylate chains and drastically reduce the SAP swelling capacity [37, 40-43]. However, the effect of anion type and valency is relatively small. Both SAP swell slightly more in $\mathrm{NaOH}$ than that in $\mathrm{NaCl}$, probably because $\mathrm{NaOH}$ neutralises the acrylic acid in the SAP and increases the osmotic swelling pressure.

Fig. 7 shows the effect of increasing saline concentration on SAP swelling by adding $\mathrm{NaCl}$ to a $\mathrm{CaCl}_{2}$ solution. The $\mathrm{CaCl}_{2}$ concentration was fixed at $20 \mathrm{mmol} / \mathrm{L}$ so that the initial $\mathrm{Ca}^{2+}$ concentration is similar to the synthetic pore solutions used in Section 3.1. The concentration of $\mathrm{NaCl}$ was gradually increased to simulate an increase in alkalinity. The results show that absorption was initially very low because of the $\mathrm{Ca}^{2+}$ complexation as described earlier. However, swelling gradually increases with increase in $\mathrm{NaCl}$, despite an increase in total concentration of the test solution. This effect is stronger for S5, where the swelling ratio increased by about a factor of 3, from $6 \mathrm{~g} / \mathrm{g}$ to $18 \mathrm{~g} / \mathrm{g}$, when the concentration of $\mathrm{NaCl}$ increased from 0 to $1200 \mathrm{mmol} / \mathrm{L}$. The increase in swelling ratio despite an increase in total saline concentration is rather unexpected and this is also observed when swelling ratio was measured in synthetic pore solutions (Fig. 3). The results show that absorption capacity is not a simple function of saline concentration or ionic strength. It appears $\mathrm{Ca}^{2+}$ is much more effective in restraining the swelling of SAP compared to the other ions. However, addition of $\mathrm{Na}^{+}$produces a partial recovery in swelling. This effect will be further investigated in subsequent sections. 


\subsection{Effect of repeated wetting and drying on swelling ratio}

Fig. 8 shows the effect of repeated wetting and drying on SAP swelling in $\mathrm{NaCl}$ and $\mathrm{CaCl}_{2}$ solutions. Details of the test solutions and cyclic conditions used are described in Table 4 (Regimes A to D). The results show that when cyclic wetting and drying was carried out in $\mathrm{NaCl}$, the swelling ratios of both polymers remained approximately constant at $\sim 80 \mathrm{~g} / \mathrm{g}$ for each cycle. This shows that SAP can repeatedly collapse on drying and re-swell on wetting with no apparent loss in swelling capacity in $\mathrm{NaCl}$. This swelling reversibility is obviously a desirable property for certain applications such as crack sealing.

However, when tested in $\mathrm{CaCl}_{2}$, both polymers displayed a substantial loss in absorption capacity for each cycle. The swelling ratio of S2 drops to almost zero beyond the third cycle, while S5 achieves a stable value at $\sim 25 \mathrm{~g} / \mathrm{g}$ beyond the fourth cycle. The rate of decrease in swelling is greater in the $3.2 \mathrm{mmol} / \mathrm{CaCl}_{2}$ solution compared to that of the $1.6 \mathrm{mmol} / 1 \mathrm{CaCl}_{2}$ solution. However, the swelling ratios in both solutions converge to a similar value as the number of cycles increased. It is also noted that cyclic wetting in a solution containing equal amounts of $\mathrm{NaCl}$ and $\mathrm{CaCl}_{2}$ did not significantly alter the swelling behaviour of the SAP.

Fig. 9 shows the effect of repeated exposure to $\mathrm{NaCl}$ after an initial cycle in either $\mathrm{CaCl}_{2}, \mathrm{Ca}\left(\mathrm{NO}_{3}\right)_{2}$ or the synthetic 'strong' pore solution (PS1) (Regimes E to F, Table 4). It can be observed that exposure to $\mathrm{CaCl}_{2}, \mathrm{Ca}\left(\mathrm{NO}_{3}\right)_{2}$ or synthetic pore solution in the first cycle produced very low swelling for both polymers. However, the swelling gradually recovers when the same polymer is exposed to $\mathrm{NaCl}$ in subsequent cycles. The results also show that S5 recovers much faster than S2. A complete recovery of the swelling ratio appears to be possible, particularly for S5 if the cyclic wetting/drying is extended.

The loss in absorption capacity with each wetting/drying cycle in calcium bearing solution suggests that there is gradual binding between $\mathrm{Ca}^{2+}$ and acrylate chains in the SAP. The binding is cumulative and occurs even in low $\mathrm{Ca}^{2+}$ concentrations. For crack sealing, this effect is undesirable since calcium is found in many exposure environments (groundwater for example) and calcium is leached when flow occurs through cracks. The $\mathrm{Ca}^{2+}$ complexation can lead to ineffective crack sealing. However, if the SAP is exposed to $\mathrm{NaCl}$ in subsequent cycles (Fig. 9), swelling gradually recovers because the complexes can be removed when monovalent cations are available to displace the $\mathrm{Ca}^{2+}$ from acrylate chains via ion exchange. This is consistent with the results shown in Figs. 3 and 7.

\subsection{Effect of alkalinity and calcium content on SAP swelling in cement paste}

Fig. 10 shows the swelling ratio of SAP in cement pastes that contain a range of alkalinity and calcium content in the pore solution. Note that alkalinity and calcium content were varied by adding dissolved sodium hydroxide and calcium nitrate to the batch water, and swelling ratio was measured using image analysis as described in Section 2.4. The cement paste samples are from Series I and II (Table 3) that were made with white Portland cement. The error bars represent the standard error of the measurements. The results show that pore solution alkalinity and calcium content have strong influences on SAP absorption capacity. The swelling ratios for both SAPs increase with increase in alkalinity, but decrease with increase in 
calcium concentration. Swelling ratio increased from $\sim 2.5 \mathrm{~g} / \mathrm{g}$ at $0.09 \%$ equivalent $\mathrm{Na}_{2} \mathrm{O}$ to more than $16 \mathrm{~g} / \mathrm{g}$ at $0.9 \%$ equivalent $\mathrm{Na}_{2} \mathrm{O}$ content. When the calcium nitrate content was increased to $4 \%$ wt. cement, the swelling ratio of S5 in cement paste dropped to less than $1 \mathrm{~g} / \mathrm{g}$, while the swelling ratio of S2 remained very low over the entire range of calcium nitrate. The results also show that S2 swells significantly less than S5, consistent with previous results in synthetic pore solutions.

It can be seen that the SAP swelling ratios measured in hardened cement paste are close, but slightly lower than the free swelling ratios measured in synthetic pore solutions (Fig. 3). This discrepancy may be due to the fact that the composition of real pore solution is much more complex and variable because of the dissolution and precipitation processes occurring during hydration. The SAP may lose part of the absorbed water before setting due to cumulative binding with $\mathrm{Ca}^{2+}$ and so the measured swelling ratio on hardened paste will be lower than that measured in fresh state. This was seen in our results (Fig. 3) for S2 and was also observed by Schroefl et al. [23, 27]. Furthermore, mixing and compaction during batching induce physical confinement that will reduce the absorption capacity of the SAP relative to its free swelling. It should also be noted that the absorption of SAP was measured in hardened cement pastes instead of mortars or concretes for the sake of simplicity and convenience. Presence of aggregate particles will not significantly change the pore solution composition, but it provides another physical restraint to the swelling of SAP. Further work is required to establish whether this has a significant effect on the absorption capacity of SAP.

A comment should be made regarding the image analysis method used for determining the swelling ratio of SAP in cement paste. The reliability of this method depends on the contrast between SAP voids and cement paste, which was enhanced via the surface treatment described in Section 2.4. There are other methods, for example BSE image analysis [32], X-ray computed tomography [44], NMR relaxation [45] and neutron tomography [46]. Each of these has advantages and limitations. We used a flatbed scanner because it is relatively straight forward and allows a large sample area to be measured rapidly. However, the method requires the dried SAP to be removed and this can be problematic if it bonds strongly to the cement paste. The method is also limited by the resolution of the scanner and so may be inappropriate for SAP with particle sizes much smaller than those used in this study. The method requires testing of a companion control sample with no SAP and assumes it has the same entrapped air to that of cement paste containing SAP. This may not be strictly valid in some cases since the swollen SAP affects the rheology of the fresh cement paste.

\subsection{Pore solution composition and ion exchange}

The compositions of the pore solutions extracted from white Portland cement pastes containing 2\% S2 at various times after mixing are shown in Table 5. The analysis using ICP-OES and acid-base titration found that the pore solution contained mainly $\mathrm{Na}^{+}, \mathrm{K}^{+}, \mathrm{Ca}^{2+}, \mathrm{SO}_{4}{ }^{2-}$ and $\mathrm{OH}^{-}$, while other elements were in trace quantities. The measured concentrations of $\mathrm{OH}^{-}$are reasonably close to the calculated values, thus giving confidence in the measured values. The results show that the concentration of $\mathrm{Na}^{+}$was consistently very high, from the earliest measurement at 40 minutes $(228 \mathrm{mmol} / \mathrm{L})$ to the final measurement at $8.5 \mathrm{~h}(253$ $\mathrm{mmol} / \mathrm{L}$ ). In contrast, the concentration of $\mathrm{Na}^{+}$for the control WPC paste without SAP was only $\sim 7 \mathrm{mmol} / \mathrm{L}$ 
(Series IV, Table 6). This shows that the presence of SAP increases the concentration of alkali $\left(\mathrm{Na}^{+}\right.$for S2) and this occurs very soon after mixing. The concentration of $\mathrm{K}^{+}$was also relatively constant $(\sim 3$ to 4.5 $\mathrm{mmol} / \mathrm{L})$, but close to the value of the control paste $(\sim 3 \mathrm{mmol} / \mathrm{L})$. The total alkalinity $[\mathrm{Na}+\mathrm{K}]$ is stable after about 4 hours after mixing. However, the concentrations of $\mathrm{Ca}^{2+}$ and $\mathrm{SO}_{4}{ }^{2-}$ decreased with increase in time. The reason for the decline is due to precipitation of hydration products (particularly ettringite), but it could also be partly due to ion exchange with the SAP (discussed later). The concentration of $\mathrm{OH}^{-}$increased with time and this is attributable to the continuous dissolution of the cement phases.

Table 6 shows the composition of pore solutions extracted after $\sim 4$ hours of mixing (between 245 and $280 \mathrm{~min}$ ) from a range of cement pastes from Series III to VI. The objective is to study the effect of SAP type and amount on the pore solution composition, to establish if ion exchange occurs between SAP and pore solution, and how this influences SAP swelling. Since the concentration of alkalis during the first few hours of hydration (dormant period) is relatively constant [47-49] and because the pore solutions were measured at the same time, the observed changes in alkali concentration must be indicative of the exchange process between the SAP and pore solution. Furthermore, the SAP itself should not influence hydration kinetics at such an early age.

The results show that the pore solutions from WPC pastes (Series IV) have lower alkali content compared to that of the CEM I pastes (Series III), as expected. The pore solution from WPC paste also show consistently higher $\mathrm{Ca}^{2+}$ content and lower $\mathrm{SO}_{4}{ }^{2-}$ compared to that of the CEM I paste. The WPC pastes with added sodium hydroxide (Series V) gave the highest alkali content, as expected. It is also noted that the concentration of $\mathrm{Na}^{+}$for the WPC $+\mathrm{NaOH}$ control paste (no SAP) compares well with the known amount of sodium hydroxide added and this shows that the sodium hydroxide remains dissolved in the pore solution after 4 hrs of hydration. This is also the case for the pastes with added calcium nitrate (Series VI).

When the pore solutions of pastes containing SAP are compared against their respective reference control paste, it can be seen that the presence of SAP increases the concentration of alkalis significantly; S2 (poly AA) increases the concentration of $\mathrm{Na}^{+}$, while the presence of S5 (poly AA-co-AM) increases the concentration of $\mathrm{K}^{+}$. However, pastes containing SAP registered a drop in concentration of $\mathrm{Ca}^{2+}$. To examine this further, data from Table 6 are used to plot the change in concentration of alkalis $\left(\Delta C_{\mathrm{Na}+\mathrm{K}}\right)$ and calcium $\left(\Delta C_{C a}\right)$ in pastes containing SAP relative to the control in Figs. 11 to 13. Fig. 11 shows that all samples displayed positive $\Delta C_{N a+K}$ values, indicating the release of $\mathrm{Na}^{+}$and $\mathrm{K}^{+}$from the SAP into the pore solution. All samples bar one showed negative $\Delta C_{C a}$ values, indicating that $\mathrm{Ca}^{2+}$ is absorbed by the SAP. However, the magnitudes of $\Delta C_{\mathrm{Na}+K}$ are not strongly correlated to $\Delta C_{\mathrm{Ca}}$ and this is probably due to the fact that the calcium content is also affected by dissolution of cement and precipitation of hydration products. Overall, the degree of ion exchange is higher in pastes containing S2. Furthermore, the degree of ion exchange decreases with increase in alkalinity, and this correlates well to the observed increase in swelling 
ratio of the SAP. S5 has the highest swelling ratio and it is also more resistant to ion exchange compared to S2.

Addition of dissolved calcium nitrate increases the concentration of $\mathrm{Ca}^{2+}$ in the pore solution substantially, as seen in Table 6 (Series VI). Fig. 12 and Fig. 13 show that increasing $\mathrm{Ca}^{2+}$ content in the pore solution increases the magnitude of $\Delta C_{\mathrm{Na}+K}$ and $\Delta C_{\mathrm{Ca}}$. Therefore, the amount of ion exchange and $\mathrm{Ca}^{2+}$ complexation increases and this depresses the swelling of the SAP. WPC pastes without calcium nitrate display the lowest $\Delta C_{C a}$ because their $\mathrm{Ca}^{2+}$ concentration $(\sim 50 \mathrm{mmol} / \mathrm{L})$ is relatively small such that the lost of $\mathrm{Ca}^{2+}$ ions to SAP can be partially replenished by dissolution of the cement phases. In contrast, the pore solution of WPC pastes containing calcium nitrate is already supersaturated with $\mathrm{Ca}^{2+}(>400 \mathrm{mmol} / \mathrm{L})$, so this effect is less significant. It can also be seen that increasing the SAP content in the cement paste increases the magnitude of $\Delta C_{N a+K}$ and $\Delta C_{C a}$, which is again consistent with expectation. The results also show that S5 has the higher swelling ratio and exhibits lower ion exchange compared to S2.

The results consistently show that the presence of $\mathrm{S} 2$ increases $\left[\mathrm{Na}^{+}\right]$in pastes while $\mathrm{S} 5$ increases $\left[\mathrm{K}^{+}\right]$ (Table 6) because these counter-ions are released from the SAP in exchange with $\mathrm{Ca}^{2+}$ ions from the pore solution that binds with the acrylate chains. Increasing the $\mathrm{Ca}^{2+}$ content in the pore solution by adding dissolved $\mathrm{Ca}\left(\mathrm{NO}_{3}\right)_{2}$ increases $\mathrm{Ca}^{2+}$ complexation and this depresses swelling further (Figs. 10b, 12 \& 13). In contrast, increasing the alkalinity of the pore solution (Figs. 10a \& 11) increases SAP swelling because it inhibits ion exchange and therefore $\mathrm{Ca}^{2+}$ complexation. These are significant factors controlling swelling of SAP in cement paste in addition to osmotic pressure. The higher the degree of ionic exchange, the lower the swelling ratio of the SAP, and vice versa. The results are consistent with the measurements made in weak/strong synthetic pore solution (Fig. 3), in $\mathrm{NaCl}+\mathrm{CaCl}_{2}$ solution (Fig. 7) and in the cyclic wetting/drying experiments (Fig. 9).

\subsection{SEM-EDX analysis}

Figs. 14 and 15 show backscattered electron (BSE) images and energy dispersive X-ray (EDX) element maps of samples containing SAP. The first sample contained dry SAP (S2) mixed with CEM I and cast in a low-viscosity epoxy. The second sample is a CEM I cement paste containing S2. EDX mapping shows that the dry SAP (Fig. 14) contains mainly sodium, carbon and oxygen, which is consistent with the type of polymer used. However, when the SAP is cast into cement paste (Fig. 15), the EDX mapping shows that the SAP has gained a substantial amount of calcium, which must have been absorbed from the pore solution. There is also a significant gain in potassium on the SAP. These observations support the measured changes in pore solution composition presented in the previous section and the described ion exchange process that occurs between the SAP and pore solution. There is also a slightly higher content of sulphur on the surface of the SAP. However, this is due to precipitation of hydration products on the surface of the SAP as can be seen in the BSE image. Other detectable elements were Al, Mg, Si and Fe, but these were only found in the cement paste and not in the SAP. 


\section{Implications}

This study has shown that while the swelling of both polymers is similar in non-calcium bearing solutions, the swelling of poly(AA) in calcium bearing solution is reduced sharply. This can be seen from the measurements in test solutions and also in hardened cement paste. Furthermore, the swelling of S2 recovers at a much slower rate compared to S5 (Fig. 9). The difference in behaviour is because poly(AA) has a higher amount of acrylate chains than poly(AA-co-AM) and therefore is more susceptible to $\mathrm{Ca}^{2+}$ complexation. The amount of ion exchange deduced from the measured change in pore solution composition showing pastes with $\mathrm{S} 2$ consistently having greater magnitudes of $\Delta C_{N a+K}$ and $\Delta C_{C a}$ supports this. Poly(AA-co-AM) has lower acrylate content and so forms less $\mathrm{Ca}^{2+}$ acrylate complex. Furthermore, non-ionic acrylamide groups act as spacers between the acrylate groups, thus weakening the short range bonding between absorbed $\mathrm{Ca}^{2+}$ and neighbouring acrylate groups, and reducing the stability of the $\mathrm{Ca}^{2+}$ complex. The absence of acrylamide in $\mathrm{S} 2$ means that $\mathrm{Ca}^{2+}$ complex can form between close neighbouring acrylate groups and restrain its swelling capacity.

In terms of practical implications, the findings from this study suggest that the swelling kinetics of SAP could be altered to optimise a particular application in concrete. For crack sealing for example, it would be desirable to depress the initial SAP swelling in fresh concrete so that its reswelling capacity and potential for crack sealing at later age is enhanced. This is also beneficial because it decreases the SAP void content, enabling a higher SAP dosage in the mixture and limiting its negative impact on strength. Initial swelling can be suppressed by using low alkalinity cement and by increasing the calcium concentration in the pore solution. Calcium nitrate or calcium nitrite are good candidates to achieve the latter because both have high solubility and are also good corrosion inhibitors for embedded steel reinforcement. The swelling of poly(AA) is easier to suppress than poly(AA-co-AM) due to its greater susceptibility to binding with $\mathrm{Ca}^{2+}$.

In contrast, it would be desirable to increase the initial swelling of SAP in fresh concrete for the purpose of internal curing, mitigating autogeneous shrinkage and frost protection. This could be achieved by increasing alkalinity, but the risk of alkali-aggregate reaction needs to be considered. Limiting calcium concentration is also not feasible and the use of calcium based additives should be avoided. Therefore, the practical approach is probably to use SAP that is more resistant to the ion exchange process such as poly(AA-co-AM). Furthermore, a well-timed release of absorbed water is important because it can be detrimental to microstructure (e.g. by increasing w/c ratio) and efficiency of internal curing if desorption occurs too quickly. The release of absorbed water can be influenced by alkali content as shown in this study. Another factor that could influence sorption kinetics is the density of anionic groups in the SAP network as shown in previous studies [23, 24].

In addition to swelling of the SAP, this study also shows the effect of SAP as an ionic exchanger on the pore solution composition. The binding of $\mathrm{Ca}^{2+}$ ions in the solution leads to the increase in the solubility 
of $\mathrm{OH}^{-}$ions, therefore increasing the $\mathrm{pH}$ of the pore solution. This is most prominent in the WPC+ $2 \% \mathrm{~S} 2$ sample. While this will increase the degree of protection of steel reinforcement, it may also increase the vulnerability to alkali-aggregate reaction. The change of pore solution composition also affects the hydration process. For example, the increase in $\mathrm{pH}$ increases the rate of hydration of cement containing supplementary cementitious materials and the decrease in calcium content in pore solution may affect the hydrates assemblage. Further study is required to investigate the significance of these effects.

This study demonstrates the swelling and ionic exchange behaviour of SAP with acrylates and acrylamide groups in pore solutions. Indeed, there are other factors that affect the swelling property of SAP such as cross-linker type and density, and functional group type and density. This provides a much wider possibility of optimisation.

\section{Conclusions}

The effect of alkalinity and calcium concentration of the pore solution on the swelling of polyacrylate (poly AA) and polyacrylate-co-acrylamide (poly AA-co-AM) superabsorbent polymers in cement paste was investigated. The study also looked at the effect of cation and anion type, concentration, ionic strength and repeated wetting/drying on the absorption capacity of SAP. Furthermore, the effect of SAP type and dosage on the pore solution composition and the ion exchange occurring between SAP and pore solution was studied. The following conclusions can be drawn:

a) In simple test solutions, absorbency of SAP decreases with increase in concentration and ionic strength of the test solution due to reduction in osmotic pressure. However, bivalent cations such as $\mathrm{Ca}^{2+}$ in the test solution produce a much greater decrease in swelling because they bind with carboxylate groups in the acrylate chains, forming additional cross-links that inhibits swelling further. The effect of anion type and valency on swelling behaviour of SAP is relatively small.

b) Cyclic wetting/drying experiments in $\mathrm{NaCl}$ show that $\mathrm{SAP}$ can repeatedly collapse and re-swell with no apparent loss in absorption capacity. However, cyclic wetting/drying experiments in calcium bearing solutions show that absorption decreases with every cycle because of gradual binding between $\mathrm{Ca}^{2+}$ and SAP. This effect is cumulative and occurs even at low calcium concentration. If the SAP is exposed to an alkaline solution in subsequent cycles, the $\mathrm{Ca}^{2+}$ complexes are gradually removed because monovalent cations $\left(\mathrm{Na}^{+}, \mathrm{K}^{+}\right)$displace the bound $\mathrm{Ca}^{2+}$ via ion exchange. This produces a gradual recovery in swelling.

c) Significant ion exchange takes place between SAP and pore solution in cement paste. This is characterised by adsorption of $\mathrm{Ca}^{2+}$ by the SAP and the release of $\mathrm{Na}^{+}$and $\mathrm{K}^{+}$into the pore solution.

d) The calcium content and alkalinity of the pore solution have strong influences on SAP absorption capacity. Increasing $\mathrm{Ca}^{2+}$ content in the pore solution increases the amount of $\mathrm{Ca}^{2+}$ complexation and this depresses swelling. In contrast, increasing the alkalinity of the pore solution increases SAP swelling because it inhibits ion exchange and therefore $\mathrm{Ca}^{2+}$ complexation. These are significant 
factors controlling the swelling of SAP in cement paste in addition to osmotic pressure. The higher the degree of ionic exchange, the lower the swelling ratio of the SAP, and vice versa.

e) Poly (AA) type SAP is more susceptible to $\mathrm{Ca}^{2+}$ complexation and therefore achieves a lower swelling ratio compared to poly(AA-co-AM) in calcium bearing solutions. Furthermore, the release of absorbed water is more rapid and recovery in swelling capacity of poly (AA) is much slower than that of poly(AA-co-AM). The findings from this study can be applied to alter the swelling kinetics of SAP to suit a particular application in concrete, such as crack sealing or internal curing.

f) SAP such as Poly(AA) are ionic exchangers that affect pore solution composition. They increase $\mathrm{Na}^{+}$ and $\mathrm{OH}^{-}$concentration while reducing $\mathrm{Ca}^{2+}$ concentration. This may affect hydration kinetics and the development of microstructure.

\section{Acknowledgement}

We would like to thank Andrew Morris for his assistance in sample preparation, and Evonik and ETi for provision of SAP samples. This project was supported by an EPSRC Doctoral Training Award held by H.X.D. Lee. 
Table 1 Composition of the Portland cements used.

\begin{tabular}{|c|c|c|c|c|c|c|c|c|c|c|c|c|}
\hline \multirow{2}{*}{ Cement } & \multicolumn{12}{|c|}{ Oxide composition (\%) } \\
\hline & $\mathrm{SiO}_{2}$ & $\mathrm{Al}_{2} \mathrm{O}_{3}$ & $\mathrm{Fe}_{2} \mathrm{O}_{3}$ & $\mathrm{CaO}$ & $\mathrm{MgO}$ & $\mathrm{SO}_{3}$ & $\mathrm{~K}_{2} \mathrm{O}$ & $\mathrm{Na}_{2} \mathrm{O}$ & $\mathrm{EqNa}_{2} \mathrm{O}$ & $\mathrm{P}_{2} \mathrm{O}_{5}$ & Free $\mathrm{CaO}$ & $\mathrm{Cl}$ \\
\hline CEM I & 20.2 & 4.64 & 1.99 & 63.8 & 2.77 & 3.11 & 0.66 & 0.18 & 0.61 & 0.18 & 0.95 & 0.053 \\
\hline WPC & 24.0 & 3.63 & 0.47 & 69.6 & 0.69 & 2.21 & 0.12 & 0.01 & 0.09 & 0.56 & 2.0 & 0.016 \\
\hline \multirow{2}{*}{ Cement } & \multirow{2}{*}{$\begin{array}{c}\text { Specific } \\
\text { gravity }\end{array}$} & \multirow{2}{*}{\multicolumn{2}{|c|}{$\begin{array}{c}\text { Specific } \\
\text { surface area } \\
\left(\mathrm{m}^{2} / \mathrm{kg}\right)\end{array}$}} & \multicolumn{4}{|c|}{ Bogue composition (\%) } & & & & & \\
\hline & & & & $\mathrm{C}_{3} \mathrm{~S}$ & $\mathrm{C}_{2} \mathrm{~S}$ & $\mathrm{C}_{3} \mathrm{~A}$ & $\mathrm{C}_{4} \mathrm{AF}$ & & & & & \\
\hline CEM I & 3.13 & & 340 & 62.9 & 10.9 & 8.93 & 6.05 & & & & & \\
\hline WPC & 3.04 & & 430 & 69.2 & 17.0 & 8.83 & 1.43 & & & & & \\
\hline
\end{tabular}

Table 2 Properties of the SAP used.

\begin{tabular}{|c|c|c|c|c|c|c|c|c|}
\hline \multirow[b]{2}{*}{ SAP } & \multirow[b]{2}{*}{ Source } & \multirow[b]{2}{*}{$\begin{array}{l}\text { Diameter } \\
\quad(\mu \mathrm{m})\end{array}$} & \multirow{2}{*}{$\begin{array}{c}\text { Bulk } \\
\text { density } \\
\left(\mathrm{kg} / \mathrm{m}^{3}\right)\end{array}$} & \multirow[b]{2}{*}{ Polymer type } & \multicolumn{4}{|c|}{ Swelling ratio, $\mathrm{g} / \mathrm{g}$} \\
\hline & & & & & $\begin{array}{l}\text { Deionised } \\
\text { water }\end{array}$ & $\begin{array}{c}0.12 \mathrm{wt} \% \\
\mathrm{NaCl}\end{array}$ & $\begin{array}{l}\text { Synthetic } \\
\text { groundwater }\end{array}$ & $\begin{array}{c}\text { Synthetic } \\
\text { pore solution } \\
(\mathrm{PS} 1)\end{array}$ \\
\hline $\mathrm{S} 2$ & Evonik & $100-300$ & $\mathrm{n} / \mathrm{a}$ & Poly(AA) & 222 & 79 & 89 & 21 \\
\hline S5 & ETi & $1-200$ & 540 & Poly(AA-co-AM) & 208 & 73 & 71 & 23 \\
\hline
\end{tabular}

Table 3 Cement paste mixture composition. The alkalinity and calcium content was varied by using white Portland cement (WPC) and adding either $\mathrm{NaOH}$ or $\mathrm{Ca}(\mathrm{NO3})_{2}$ to the batch water.

\begin{tabular}{|c|c|c|c|}
\hline Series & Cement & Batch water* & SAP dosage ( $\%$ wt. cement) \\
\hline $\mathrm{I}$ & WPC & $\begin{array}{l}\text { Deionised water }+\mathrm{NaOH} \text { to produce } \mathrm{Na}_{2} \mathrm{O}_{\text {eq }} \text { of } \\
0.09,0.25,0.4,0.55,0.7 \text { or } 0.9 \% \text { wt. cement }\end{array}$ & $0.6 \% \mathrm{~S} 2$ or $0.6 \% \mathrm{~S} 5$ \\
\hline II & WPC & $\begin{array}{l}\text { Deionised water }+0.5,1,2,3 \text { or } 4 \% \mathrm{Ca}\left(\mathrm{NO}_{3}\right)_{2} \\
\text { wt. cement }\end{array}$ & $2 \% \mathrm{~S} 2$ or $2 \% \mathrm{~S} 5$ \\
\hline III & CEM I & Deionised water & $0 \% \mathrm{SAP}, 0.6 \% \mathrm{~S} 2$ or $0.6 \% \mathrm{~S} 5$ \\
\hline IV & WPC & Deionised water & $\begin{array}{l}0 \% \mathrm{SAP}, 0.6 \% \mathrm{~S} 2,0.6 \% \mathrm{~S} 5,2 \% \mathrm{~S} 2 \text { or } \\
2 \% \mathrm{~S} 5\end{array}$ \\
\hline $\mathrm{V}$ & WPC & $\begin{array}{l}\text { Deionised water }+\mathrm{NaOH} \text { to produce } \mathrm{Na}_{2} \mathrm{O}_{\text {eq }} \text { of } \\
0.6 \text { or } 0.9 \% \text { wt. cement }\end{array}$ & $0 \% \mathrm{SAP}, 0.6 \% \mathrm{~S} 2$ or $0.6 \% \mathrm{~S} 5$ \\
\hline VI & WPC & Deionised water $+4 \% \mathrm{Ca}\left(\mathrm{NO}_{3}\right)_{2}$ wt. cement & $\begin{array}{l}0 \% \text { SAP, } 0.6 \% \mathrm{~S} 2,0.6 \% \mathrm{~S} 5,2 \% \mathrm{~S} 2 \text { or } \\
2 \% \mathrm{~S} 5\end{array}$ \\
\hline
\end{tabular}

* Note: Free water/cement ratio was 0.6 for all mixtures. 
Table 4 Test solutions used to study the effect of repeated wetting and drying on swelling capacity.

\begin{tabular}{|c|c|c|}
\hline Regime & Designation & Test condition \\
\hline A & $20 m M \mathrm{NaCl}$ & 7 cycles in $20 \mathrm{mmol} / 1 \mathrm{NaCl}$ \\
\hline $\mathrm{B}$ & $3.2 \mathrm{mM} \mathrm{CaCl}_{2}$ & 7 cycle in $3.2 \mathrm{mmol} / 1 \mathrm{CaCl}_{2}$ \\
\hline $\mathrm{C}$ & $1.6 \mathrm{mM} \mathrm{CaCl}_{2}$ & 7 cycles in $1.6 \mathrm{mmol} / 1 \mathrm{CaCl}_{2}$ \\
\hline $\mathrm{D}$ & $1.6 m M \mathrm{CaCl}_{2}+1.6 \mathrm{mM} \mathrm{NaCl}$ & 7 cycles in $1.6 \mathrm{mmol} / 1 \mathrm{CaCl}_{2}$ and $1.6 \mathrm{mmol} / 1 \mathrm{NaCl}$ \\
\hline $\mathrm{E}$ & 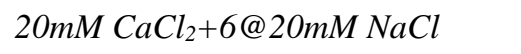 & 1 cycle in $20 \mathrm{mmol} / 1 \mathrm{CaCl}_{2}$, followed by 6 cycles in $20 \mathrm{mmol} / 1 \mathrm{NaCl}$ \\
\hline $\mathrm{F}$ & $500 m M \mathrm{Ca}\left(\mathrm{NO}_{3}\right)_{2}+6 @ 20 m M \mathrm{NaCl}$ & 1 cycle in $500 \mathrm{mmol} / 1 \mathrm{Ca}\left(\mathrm{NO}_{3}\right)_{2}$, followed by 6 cycles in $20 \mathrm{mmol} / 1 \mathrm{NaCl}$ \\
\hline G & PS1+6@20mM NaCl & 1 cycle in PS 1 , followed by 6 cycles in $20 \mathrm{mmol} / 1 \mathrm{NaCl}$ \\
\hline
\end{tabular}

Table 5 Composition of pore solution extracted from white Portland cement paste containing $2 \%$ S2 at various times after mixing.

\begin{tabular}{ccccccc}
\hline \multirow{2}{*}{$\begin{array}{c}\text { Time } \\
(\text { min })\end{array}$} & $\mathrm{Na}^{+}$ & $\mathrm{K}^{+}$ & $\mathrm{Ca}^{2+}$ & $\mathrm{SO}_{4}{ }^{2-}$ & $\mathrm{OH}^{-}$ & $\begin{array}{c}\mathrm{OH}^{-} \\
\text {(Calculated) }\end{array}$ \\
\cline { 2 - 6 } & 227.7 & 3.1 & 49.7 & 121.8 & 93.8 & 86.6 \\
80 & 236.5 & 4.1 & 31.8 & 95.1 & 117.4 & 114.0 \\
157 & 246.2 & 3.8 & 31.1 & 77.2 & 133.1 & 157.8 \\
274 & 249.3 & 3.6 & 30.3 & 68.3 & 184.4 & 176.9 \\
509 & 253.1 & 4.5 & 19.6 & 54.5 & 226.8 & 187.7 \\
\hline
\end{tabular}


Table 6 Composition of pore solution extracted from cement pastes at $\sim 4$ hours after mixing.

\begin{tabular}{|c|c|c|c|c|c|c|}
\hline \multirow{2}{*}{ Sample } & \multirow{2}{*}{$\begin{array}{l}\text { Time } \\
(\mathrm{min})\end{array}$} & \multicolumn{5}{|c|}{ Concentration (mmol/L) } \\
\hline & & $\mathrm{Na}^{+}$ & $\mathrm{K}^{+}$ & $\mathrm{Ca}^{2+}$ & $\mathrm{SO}_{4}{ }^{2-}$ & $\mathrm{OH}^{-}$ \\
\hline \multicolumn{7}{|l|}{ a) Series III: CEM I } \\
\hline CEM I (control) & 256 & 47.1 & 180.9 & 26.2 & 41.5 & 211.6 \\
\hline $\mathrm{CEM} \mathrm{I}+0.6 \% \mathrm{~S} 2$ & 254 & 114.5 & 172.9 & 24.8 & 55.4 & 257.9 \\
\hline CEM I + 0.6\% S5 & 265 & 44.4 & 194.2 & 24.5 & 49.4 & 223.9 \\
\hline \multicolumn{7}{|l|}{ b) Series IV: WPC } \\
\hline WPC (control) & 249 & 6.8 & 3.0 & 48.7 & 14.7 & 93.1 \\
\hline $\mathrm{WPC}+0.6 \% \mathrm{~S} 2$ & 252 & 82.6 & 6.9 & 32.7 & 23.3 & 127.2 \\
\hline $\mathrm{WPC}+0.6 \% \mathrm{~S} 5$ & 249 & 7.9 & 33.4 & 47.2 & 17.2 & 98.9 \\
\hline $\mathrm{WPC}+2 \% \mathrm{~S} 2$ & 274 & 249.3 & 3.6 & 30.3 & 68.3 & 184.4 \\
\hline $\mathrm{WPC}+2 \% \mathrm{~S} 5$ & 265 & 7.7 & 99.7 & 47.7 & 36.6 & 135.0 \\
\hline \multicolumn{7}{|l|}{ c) Series $\mathrm{V}: \mathrm{WPC}+\mathrm{NaOH}$} \\
\hline $\mathrm{WPC}+0.9 \% \mathrm{Na}_{2} \mathrm{O}_{\mathrm{e}}$ (control) & 253 & 424.6 & 5.1 & 16.4 & 60.3 & 376.7 \\
\hline $\mathrm{WPC}+0.9 \% \mathrm{Na}_{2} \mathrm{O}_{\mathrm{e}}+0.6 \% \mathrm{~S} 2$ & 253 & 478.8 & 4.1 & 9.5 & 77.6 & 431.5 \\
\hline $\mathrm{WPC}+0.6 \% \mathrm{Na}_{2} \mathrm{O}_{\mathrm{e}}($ control $)$ & 278 & 290.8 & 4.6 & 24.6 & 67.5 & 253.8 \\
\hline $\mathrm{WPC}+0.6 \% \mathrm{Na}_{2} \mathrm{O}_{\mathrm{e}}+0.6 \% \mathrm{~S} 5$ & 265 & 271.3 & 32.2 & 27.7 & 77.5 & 245.1 \\
\hline \multicolumn{7}{|l|}{ d) Series VI: $\mathrm{WPC}+\mathrm{Ca}\left(\mathrm{NO}_{3}\right)_{2}$} \\
\hline $\mathrm{WPC}+4 \% \mathrm{Ca}\left(\mathrm{NO}_{3}\right)_{2}$ (control) & 250 & 7.8 & 4.2 & 428.0 & 6.0 & 80.2 \\
\hline $\mathrm{WPC}+4 \% \mathrm{Ca}\left(\mathrm{NO}_{3}\right)_{2}+0.6 \% \mathrm{~S} 2$ & 248 & 89.4 & 4.4 & 406.9 & 7.2 & 77.9 \\
\hline $\mathrm{WPC}+4 \% \mathrm{Ca}\left(\mathrm{NO}_{3}\right)_{2}+0.6 \% \mathrm{~S} 5$ & 254 & 8.3 & 36.6 & 419.9 & 11.3 & 86.9 \\
\hline $\mathrm{WPC}+4 \% \mathrm{Ca}\left(\mathrm{NO}_{3}\right)_{2}+2 \% \mathrm{~S} 2$ & 270 & 289.5 & 3.7 & 309.4 & 7.2 & 68.1 \\
\hline $\mathrm{WPC}+4 \% \mathrm{Ca}\left(\mathrm{NO}_{3}\right)_{2}+2 \% \mathrm{~S} 5$ & 255 & 8.4 & 108.4 & 395.8 & 18.7 & 103.0 \\
\hline
\end{tabular}




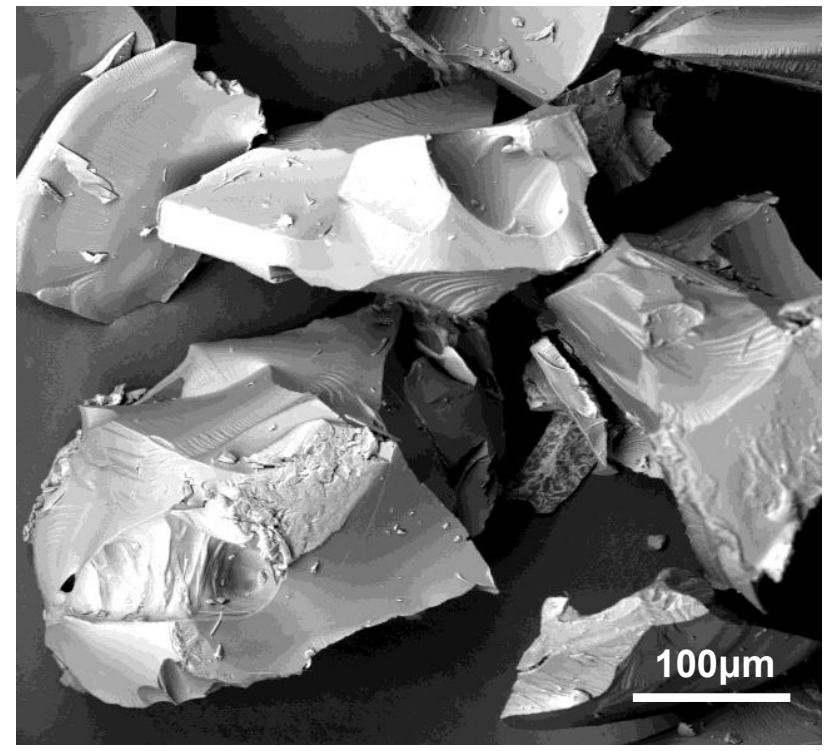

(a) S2 (poly AA)

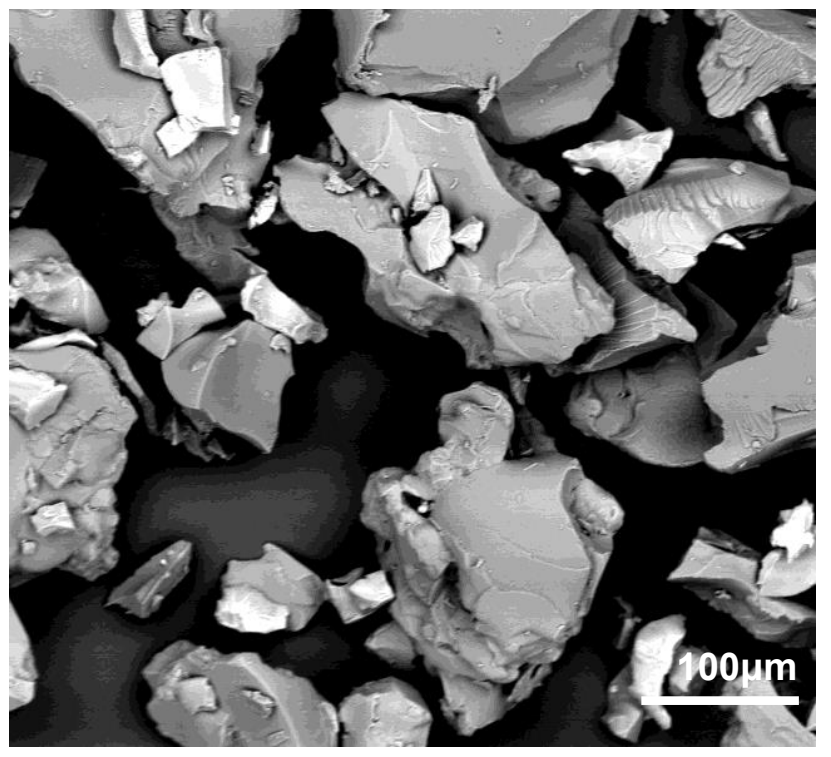

(b) S5 (poly AA-co-AM)

Fig 1 Scanning electron micrographs of the SAPs used in this study.

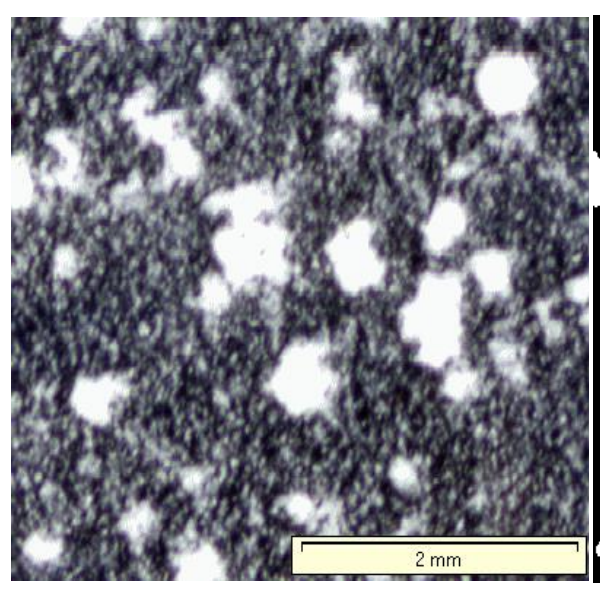

(a)

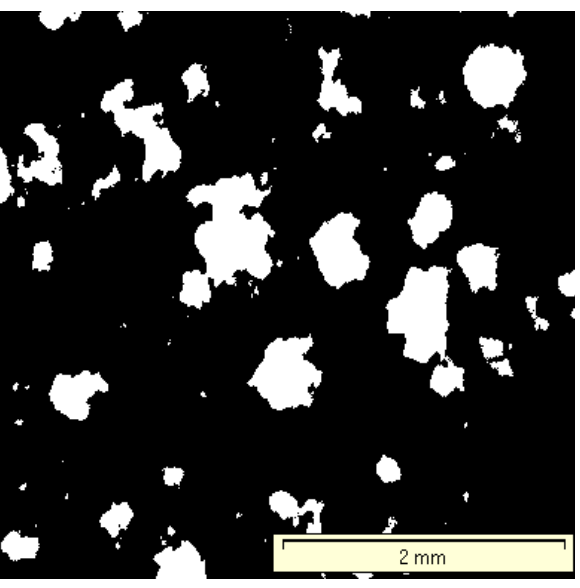

(b)

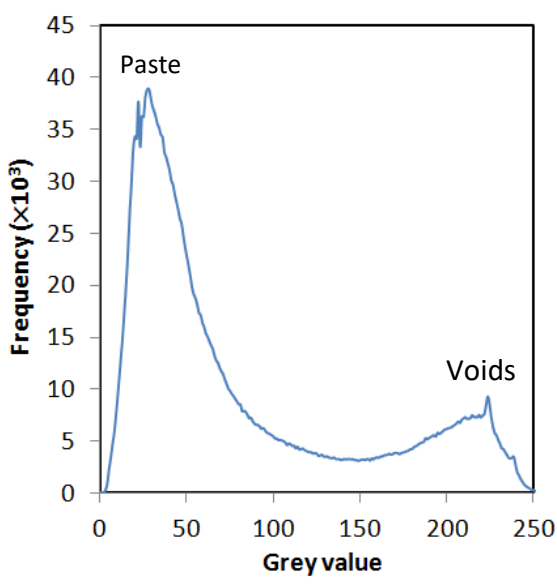

(c)

Fig. 2 a) Magnified portion from a scanned image of surface-treated cement paste showing the dark coloured paste region and voids filled with white talcum powder, b) binary image of the voids segmented by greyscale thresholding, and c) brightness histogram of the original scanned image showing peaks representing the cement paste and voids. 


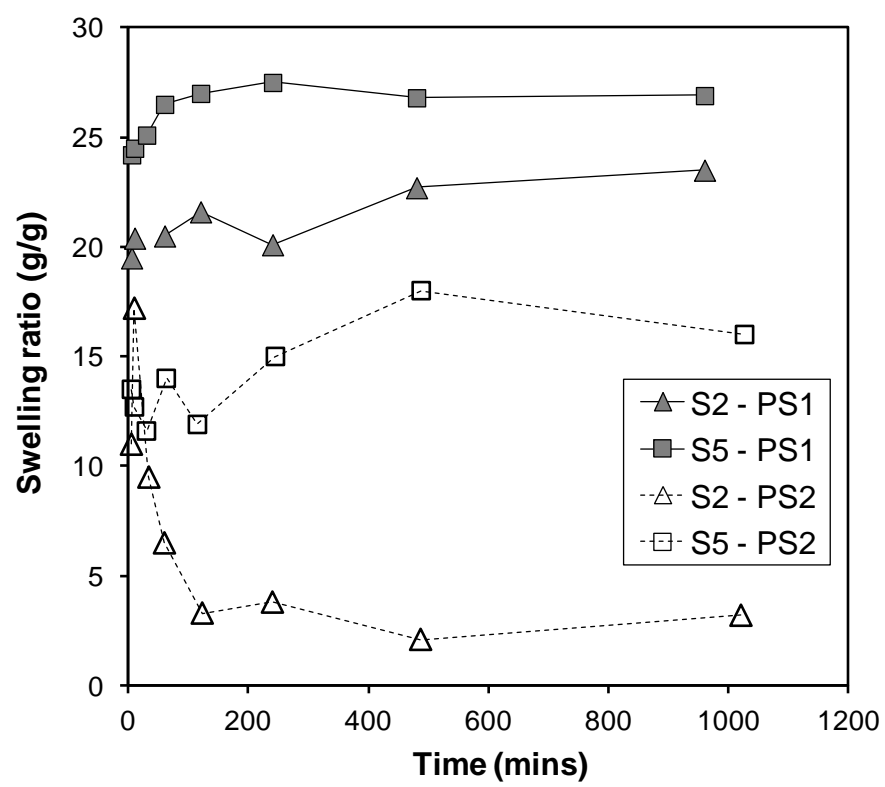

Fig. 3 Effect of exposure time on the swelling of S2 (poly AA) and S5 (poly AA-co-AM) in two synthetic pore solutions of different concentrations (PS1: 'strong', PS2: 'weak'). Swelling is highest in the 'strong' pore solution.

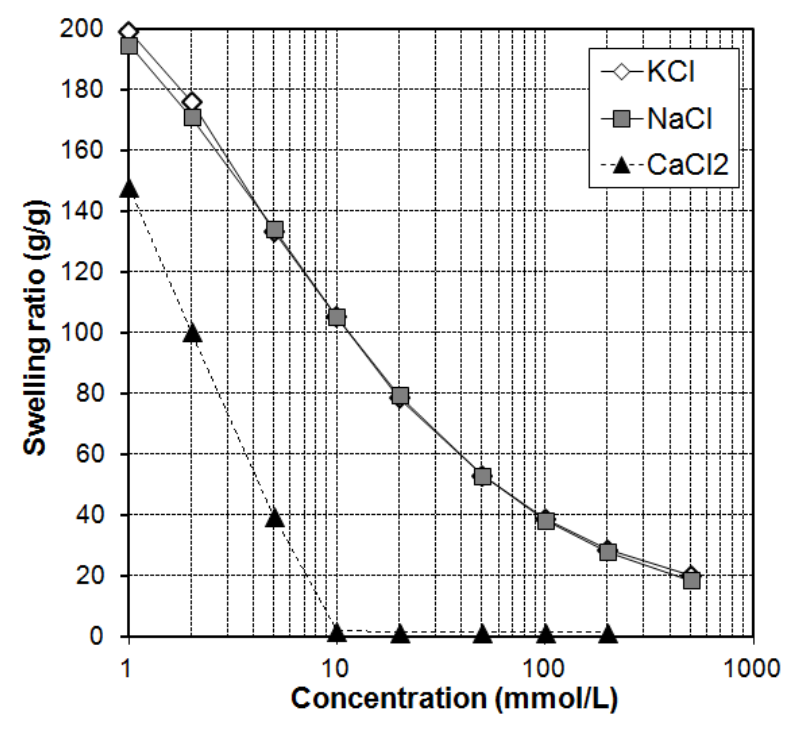

(a) S2 (poly AA)

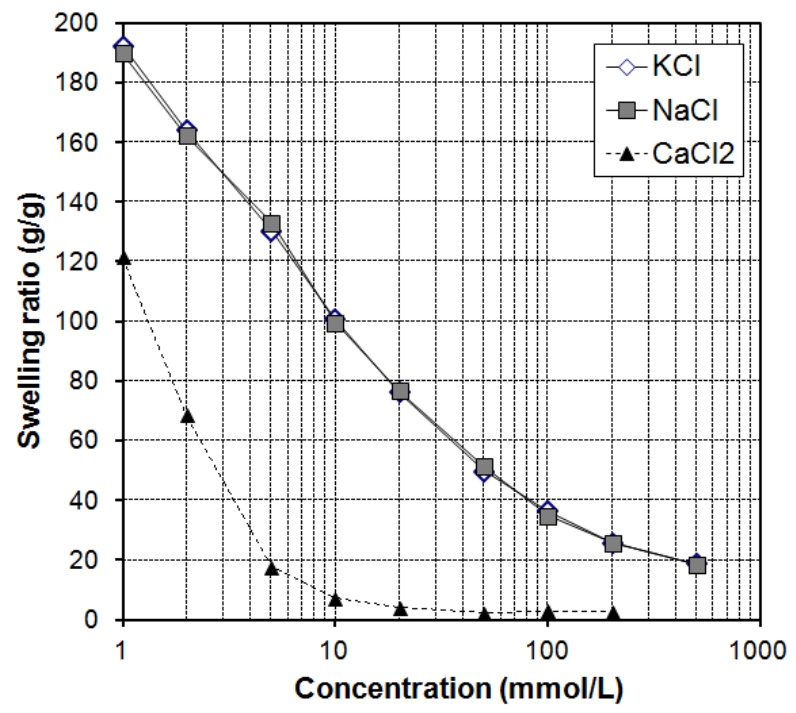

(b) S5 (poly AA-co-AM)

Fig. 4 Effect of cation type and concentration on the swelling of a) S2 (poly AA) and b) S5 (poly AA-coAM) in various chloride salt solutions. Measurements were made after 24-30 hours in solution (see Section 2.3 for details). 


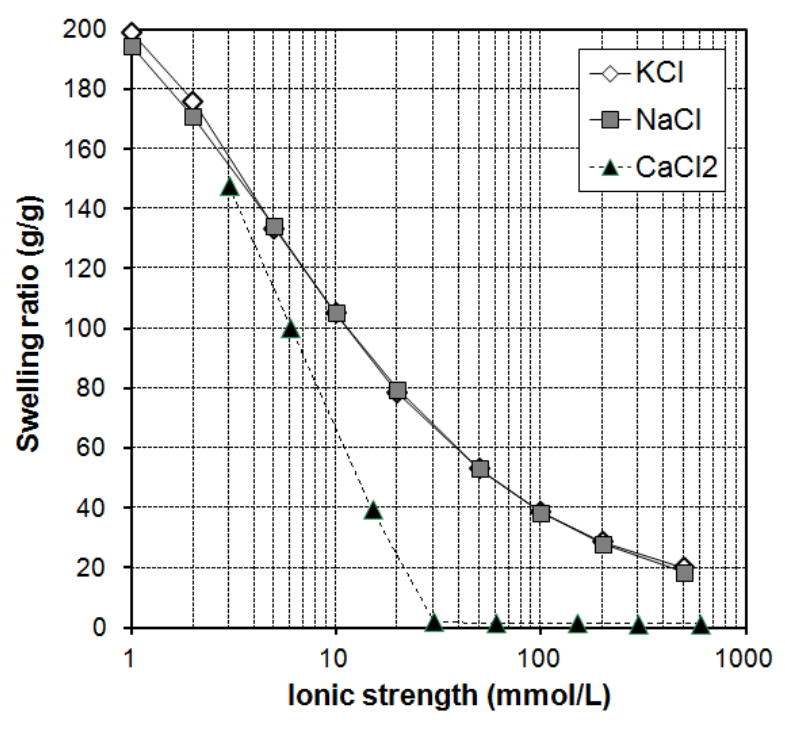

(a) S2 (poly AA)

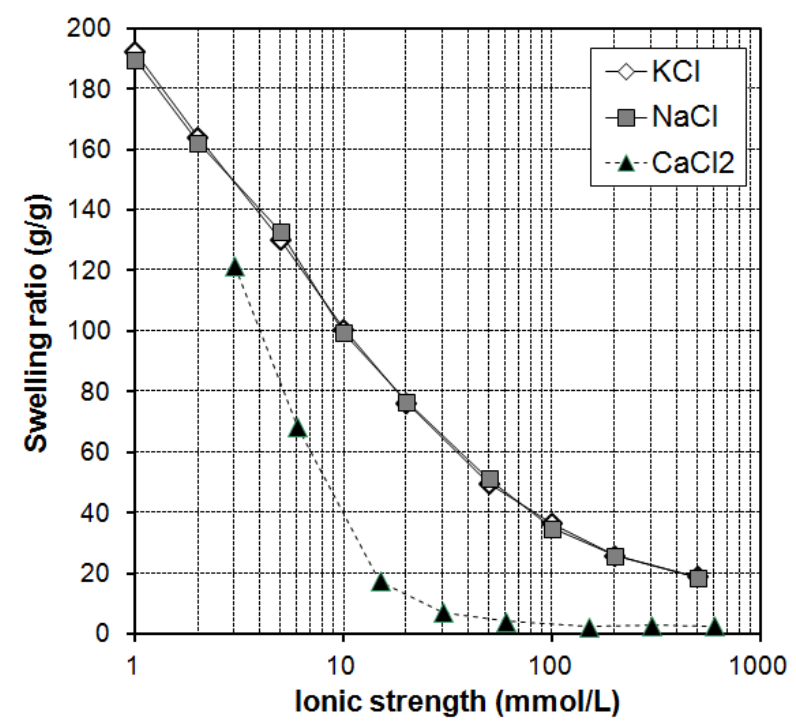

(b) S5 (poly AA-co-AM)

Fig. 5 Effect of cation type and ionic strength on the swelling ratio of a) S2 (poly AA) and b) S5 (poly AA-co-AM) in various chloride salt solutions. Measurements were made after 24-30 hours in solution (see Section 2.3 for details).

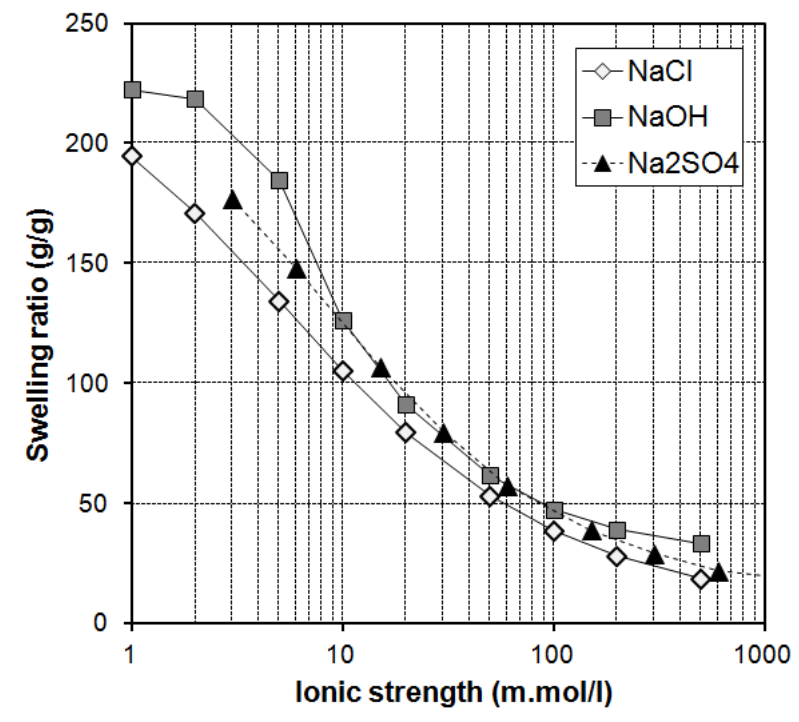

(a) S2 (poly AA)

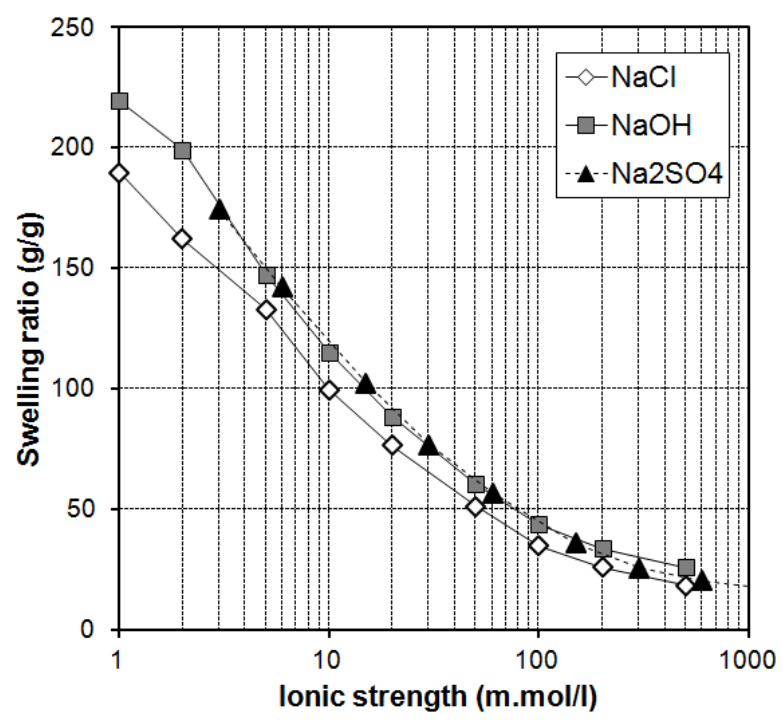

(b) S5 (poly AA-co-AM)

Fig. 6 Effect of anion type and ionic strength on the swelling of a) S2 (poly AA) and b) S5 (poly AA-coAM) in various sodium salt solutions. Measurements were made after 24-30 hours in solution (see Section 2.3 for details). 


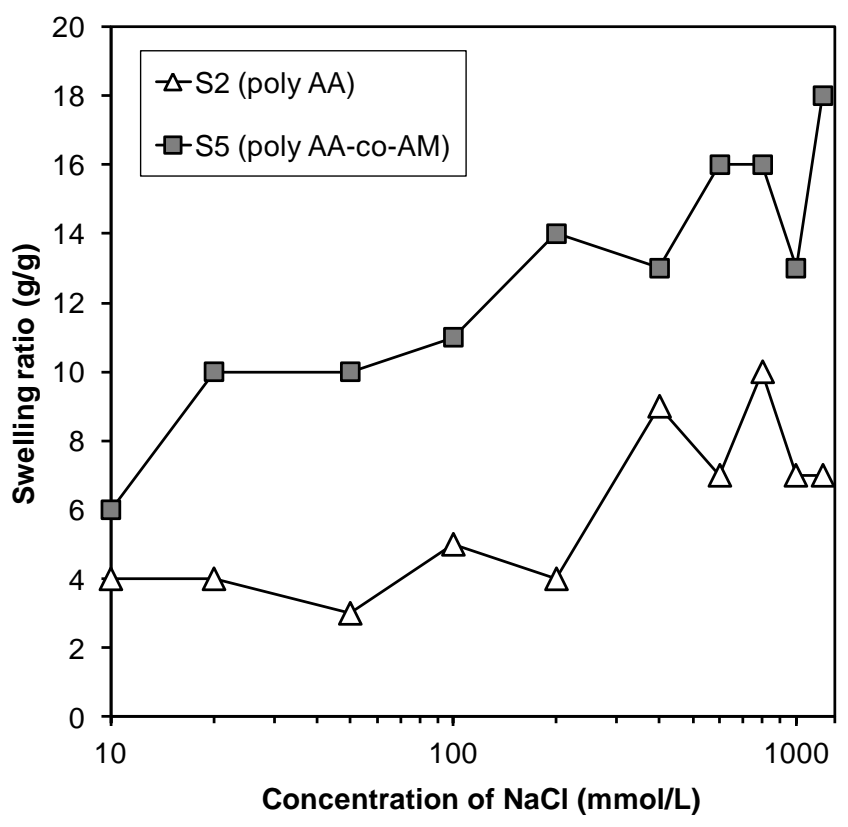

Fig. 7 Swelling ratio of $S 2$ (poly $A A$ ) and $S 5$ (poly AA-co-AM) in solutions containing $20 \mathrm{mmol} / \mathrm{L}$ $\mathrm{CaCl}_{2}$ and increasing amount of $\mathrm{NaCl}$. The swelling of $\mathrm{SAP}$ increases despite an increase in total saline concentration. Measurements were made after 24-30 hours in solution (see Section 2.3 for details).

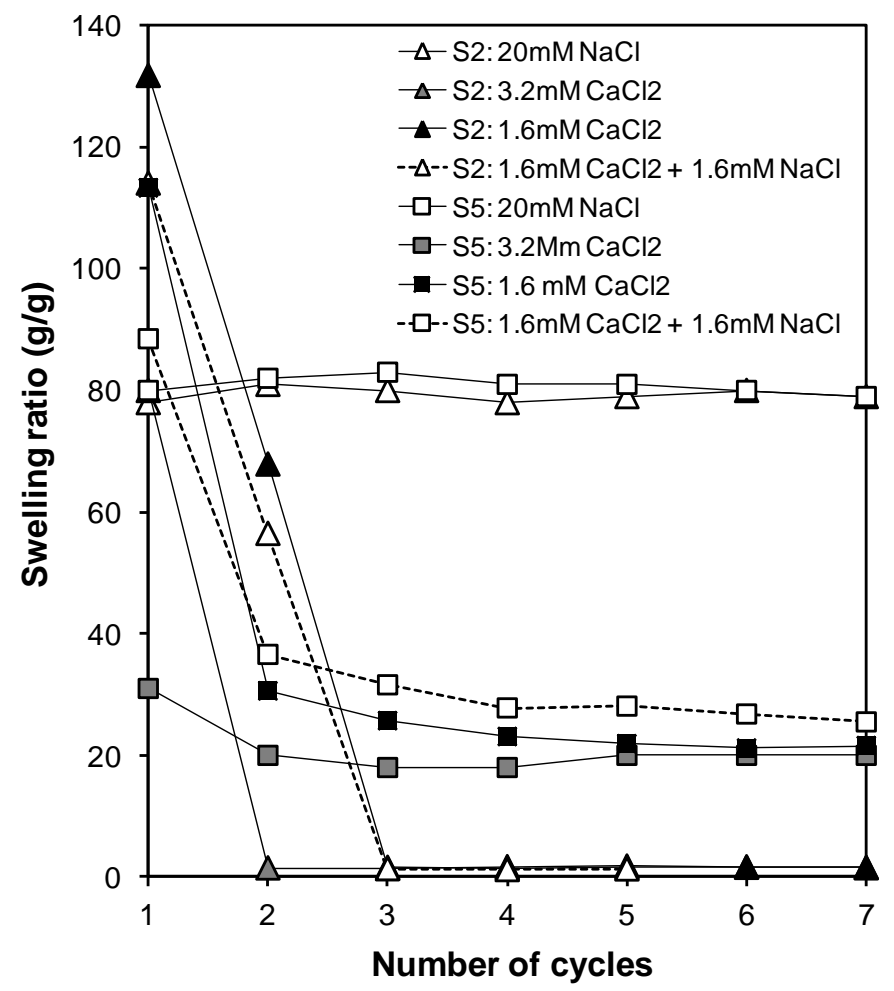

Fig. 8 Effect of repeated wetting and drying in $\mathrm{NaCl}$ and $\mathrm{CaCl}_{2}$ on the swelling ratio of $\mathrm{S2}$ (poly $\mathrm{AA}$ ) and $S 5$ (poly AA-co-AM). Both polymers show substantial reduction in absorption capacity in solutions containing $\mathrm{Ca}^{2+}$, but not $\mathrm{Na}^{+}$. 


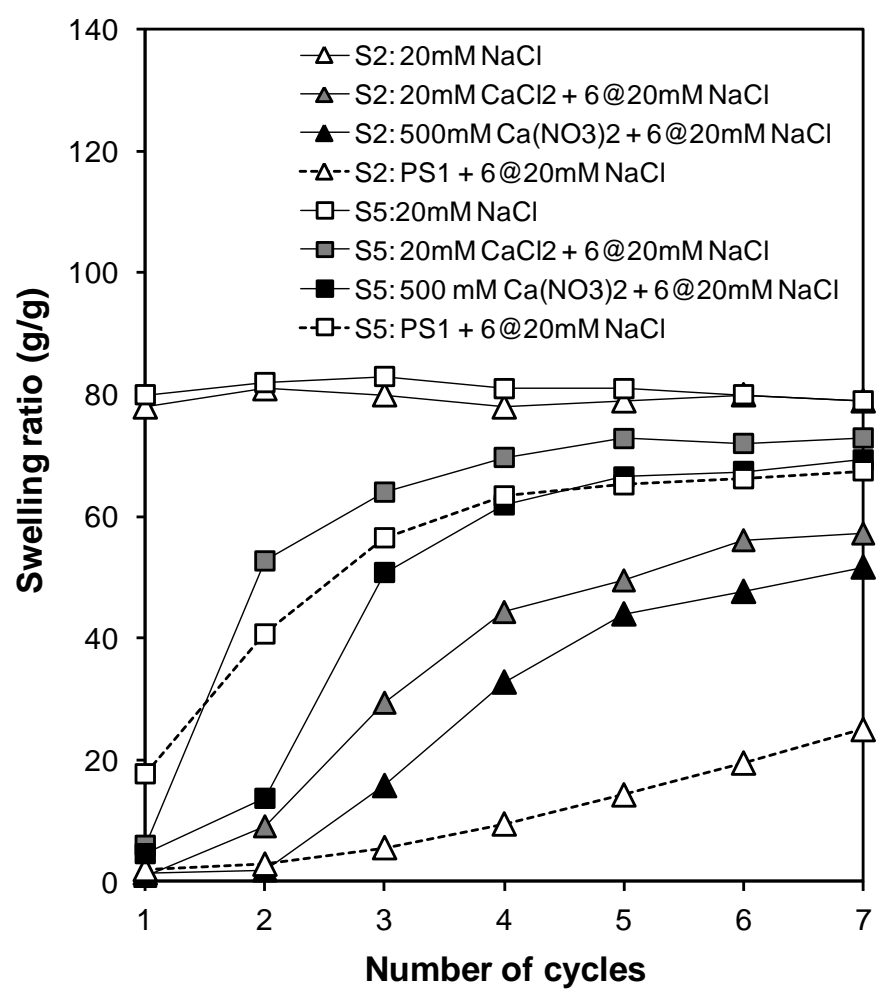

Fig. 9 Effect of repeated wetting and drying in $\mathrm{NaCl}$ after an initial cycle in either $\mathrm{CaCl}_{2}, \mathrm{Ca}\left(\mathrm{NO}_{3}\right)_{2}$ or synthetic pore solution (PS1) on the swelling ratio of S2 (poly AA) and S5 (poly AA-co-AM). Swelling of both polymers gradually recovers due to ion exchange $\left(\mathrm{Ca}^{2+}, \mathrm{Na}^{+}\right)$between pore solution and SAP.

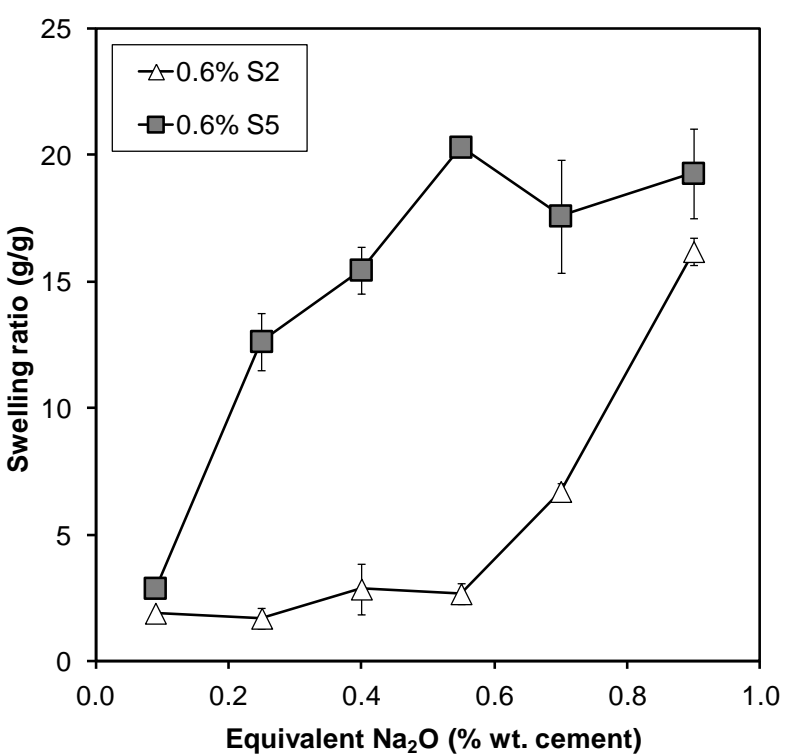

(a) Series I

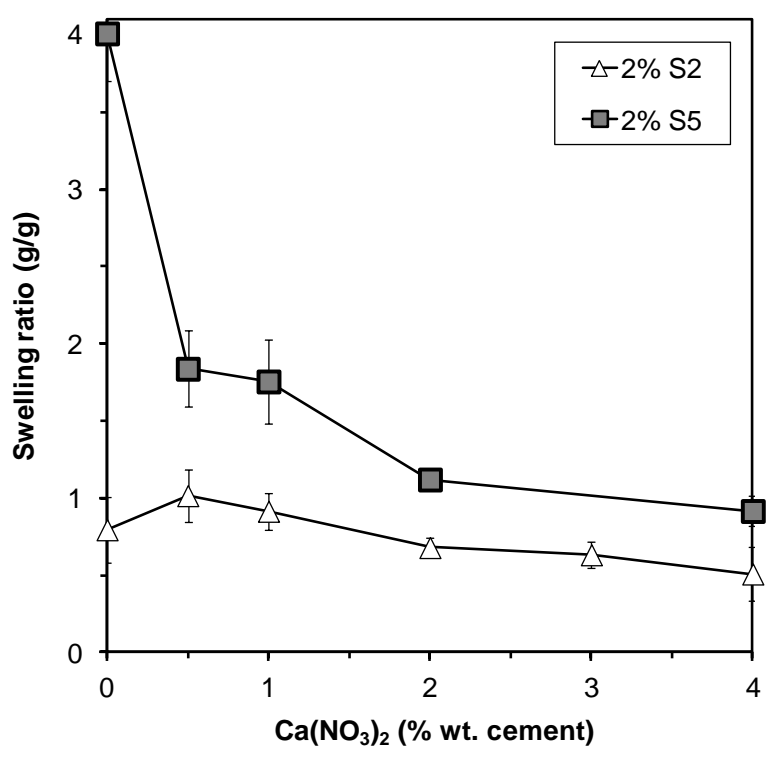

(b) Series II

Fig. 10 Effect of alkalinity (a) and calcium content (b) on the swelling of S2 (poly AA) and S5 (poly AA-co-AM) in hardened cement paste measured with image analysis. Samples are from WPC pastes from Series I and II shown in Table 3. 


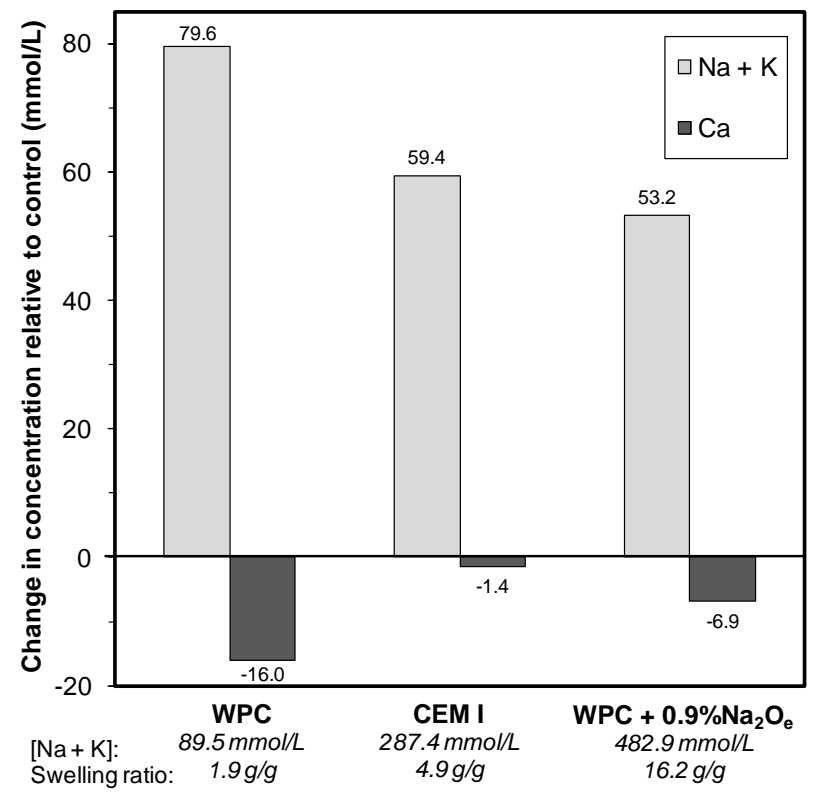

(a) $0.6 \% \mathrm{~S} 2$

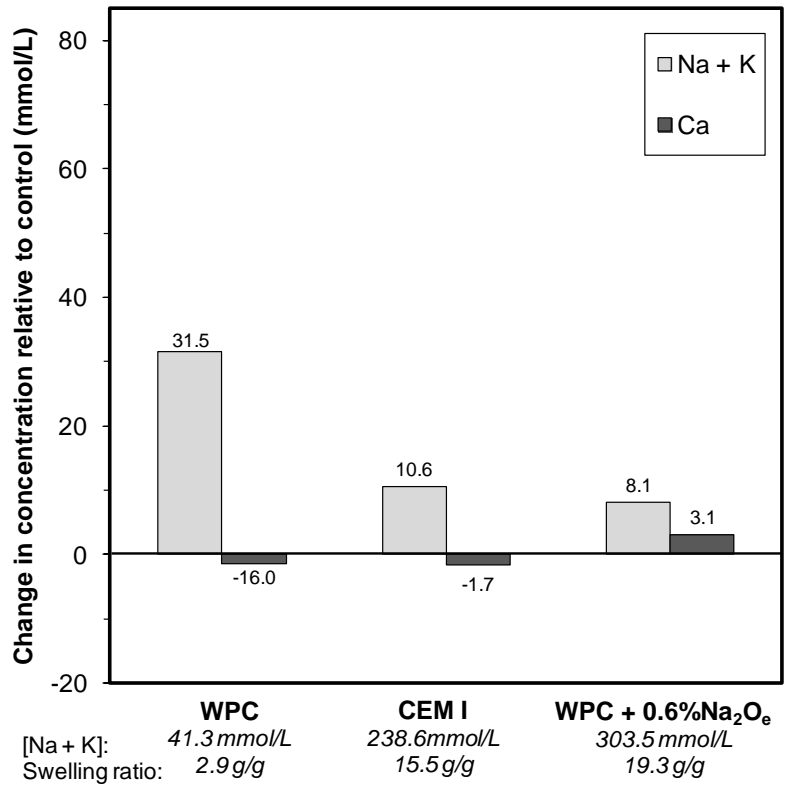

(b) $0.6 \% \mathrm{~S} 5$

Fig. 11 Effect of alkalinity and SAP on the change in pore solution composition of cement paste containing $0.6 \% \mathrm{~S} 2$ (poly AA) and $0.6 \% \mathrm{~S} 5$ (poly AA-co-AM) at $\sim 4$ hours after mixing. Ion exchange between pore solution and SAP decreases with increase in alkalinity. S5 (poly AA-co-AM) has higher swelling and resistance against ion exchange.

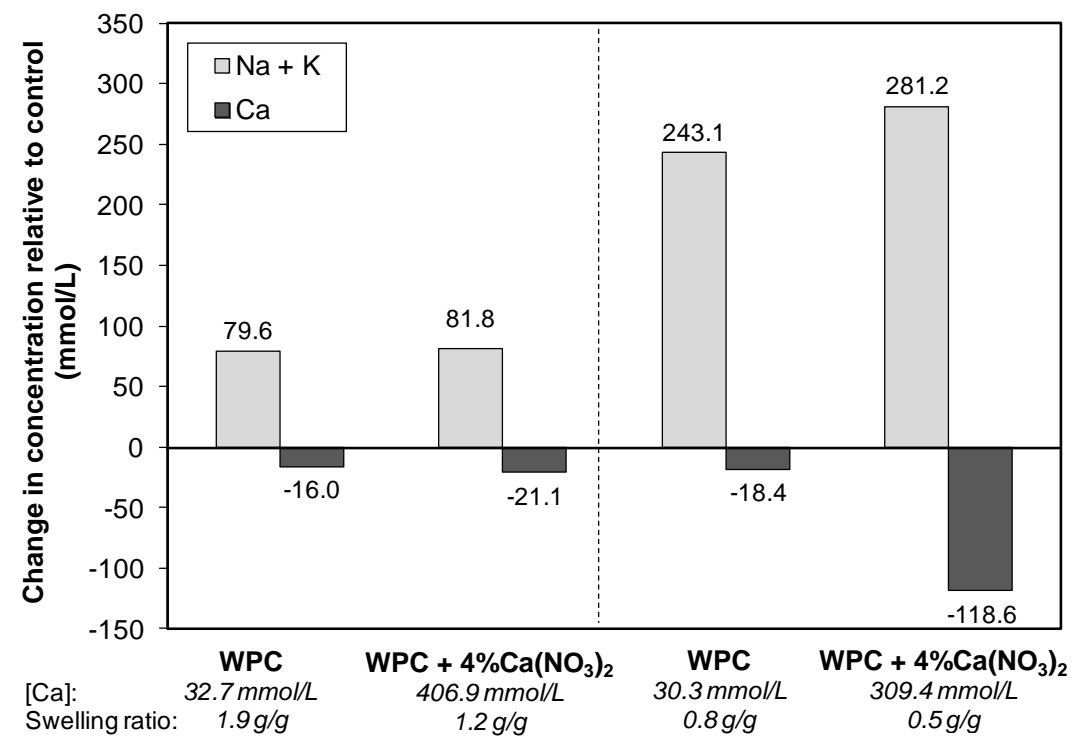

(a) $0.6 \% \mathrm{~S} 2$

(b) $2 \% \mathrm{~S} 2$

Fig. 12 Effect of calcium content and SAP on the change in pore solution composition of cement paste containing S2 (poly AA) at dosage of $0.6 \%$ and $2 \%$ at $\sim 4$ hours after mixing. Ion exchange between pore solution and SAP increases with increase in calcium content and SAP dosage. 


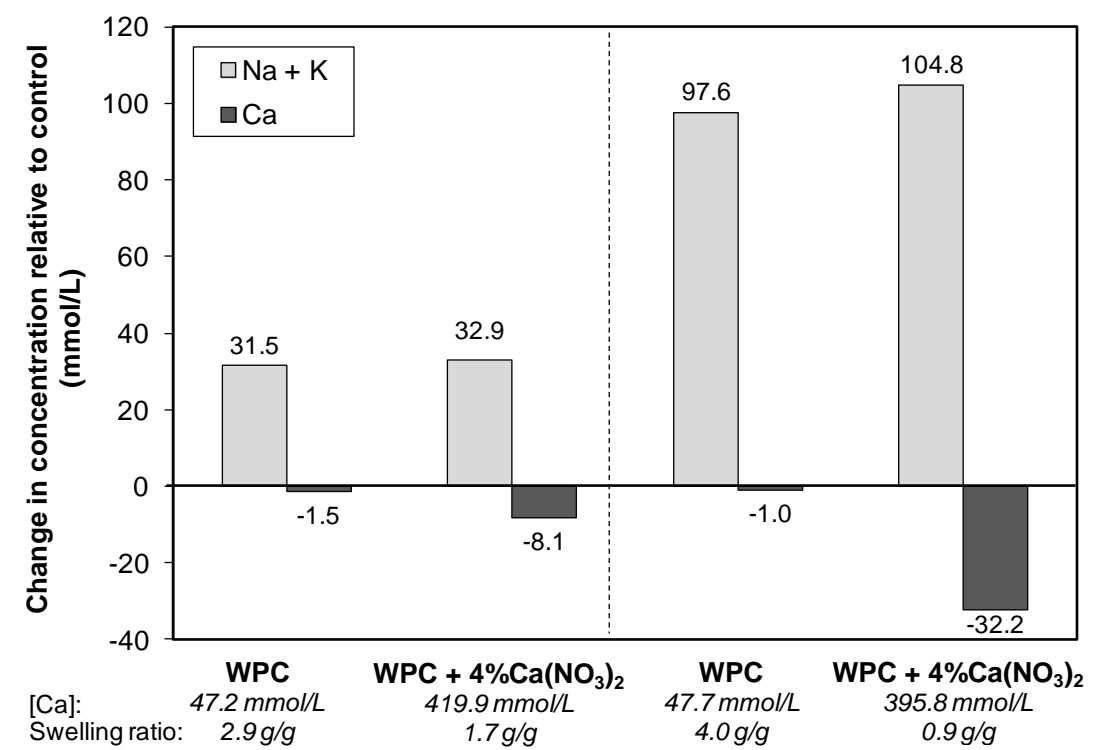

(a) $0.6 \% \mathrm{~S} 5$

(b) $2 \% \mathrm{~S} 5$

Fig. 13 Effect of calcium content and SAP on the change in pore solution composition of cement paste containing $S 5$ (poly AA-co-AM) at dosage of $0.6 \%$ and $2 \%$ at $\sim 4$ hours after mixing. Ion exchange between pore solution and SAP increases with increase in calcium content and SAP dosage.
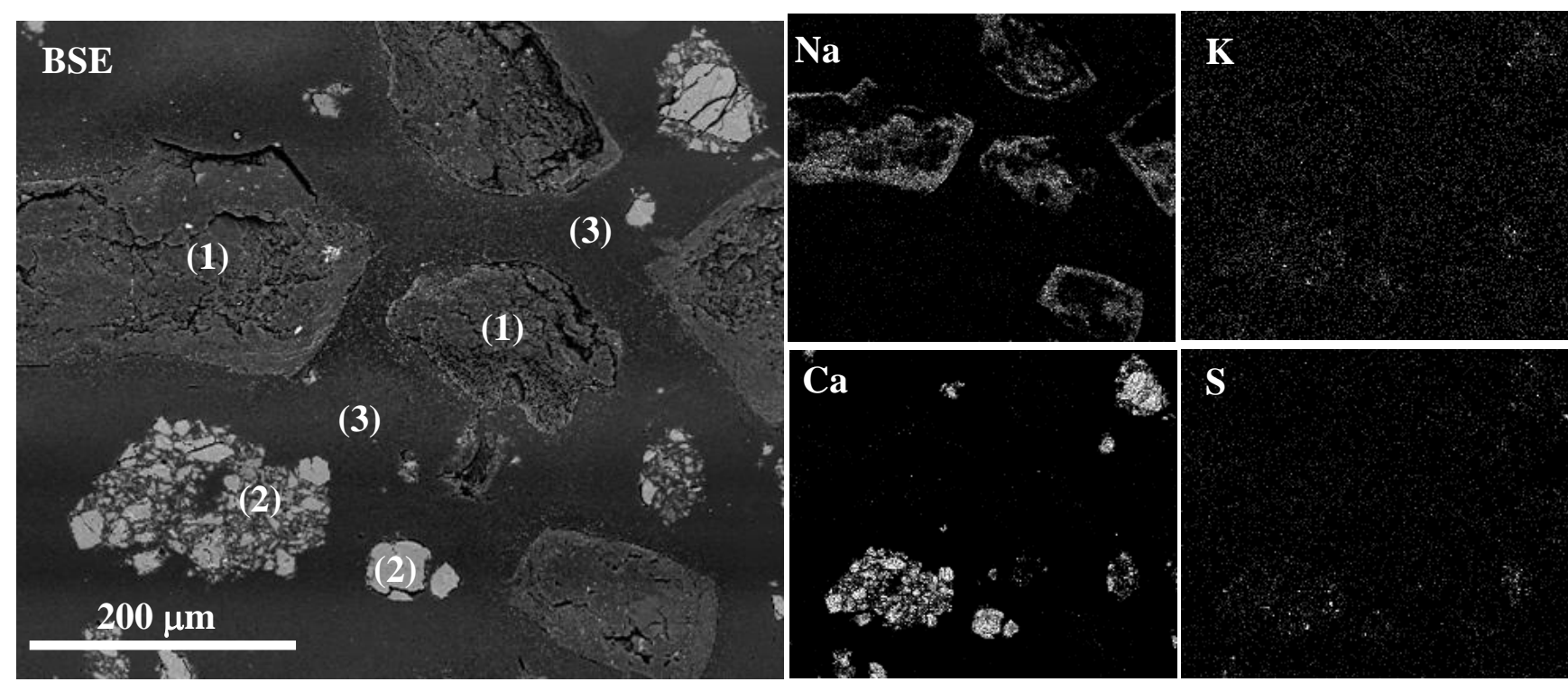

S

Fig. 14 Backscattered electron image (BSE) and energy dispersive X-ray (EDX) mapping showing the distribution of $\mathrm{Na}, \mathrm{K}, \mathrm{Ca}$ and $\mathrm{S}$ in a mixture containing dry SAP (1) and unreacted cement (2) encased in epoxy (3). 

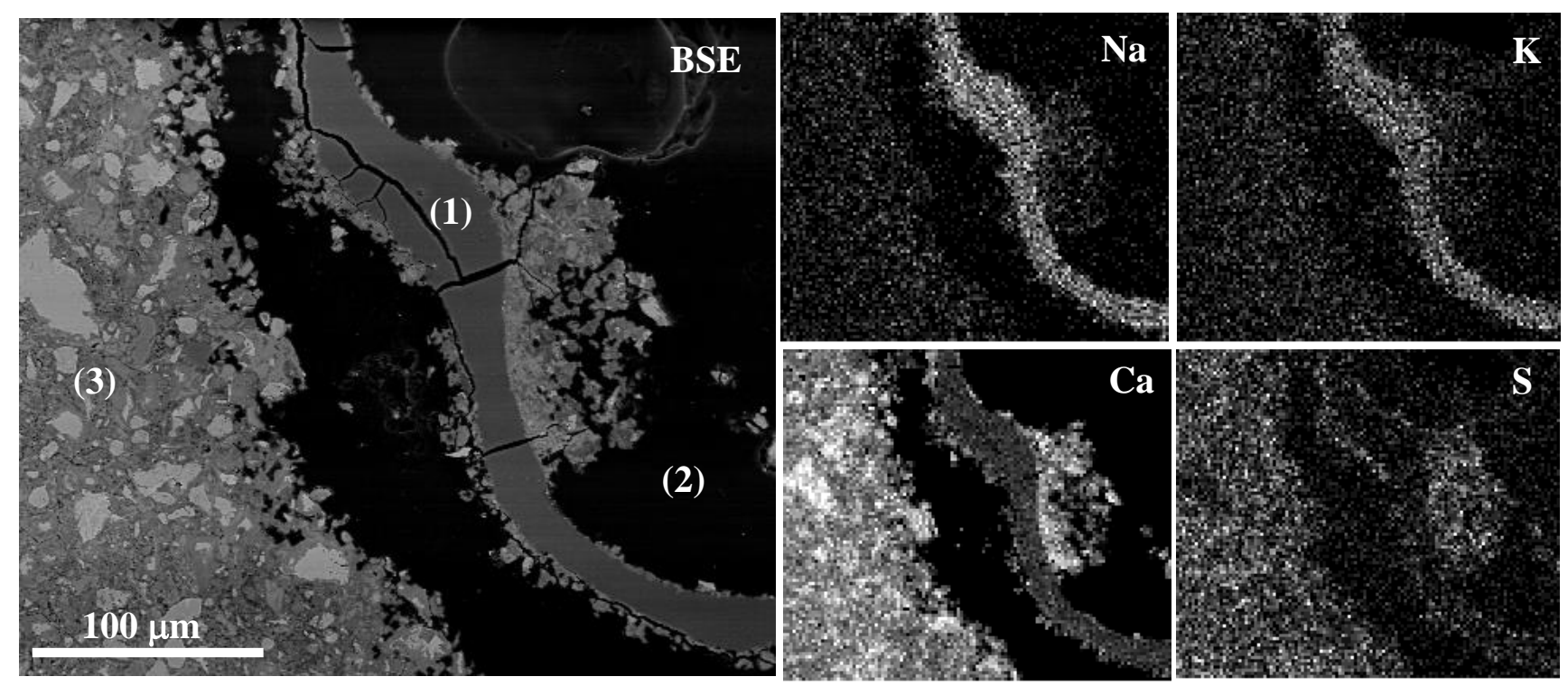

Fig. 15 Backscattered electron image (BSE) and energy dispersive X-ray (EDX) mapping showing the distribution of $\mathrm{Na}, \mathrm{K}, \mathrm{Ca}$ and $\mathrm{S}$ in cement paste containing SAP (S2-poly AA). The BSE image highlights the collapsed SAP (1), SAP void (2) and cement paste (3). Results show accumulation of Ca in the SAP due to ion exchange.

\section{References}

[1] F.L. Buchholz, A.T. Graham, Modern superabsorbent polymer technology, Wiley-VCH, New York, 1998.

[2] D.B. Stein, Handbook of hydrogels : properties, preparation \& applications, Nova Science Publishers, New York :, 2009, p. 750.

[3] O.M. Jensen, P.F. Hansen, Water-entrained cement-based materials: I. Principles and theoretical background, Cement and Concrete Research 31(4) (2001) 647-654.

[4] D.P. Bentz, O.M. Jensen, Mitigation strategies for autogenous shrinkage cracking, Cement and Concrete Composites 26(6) (2004) 677-685.

[5] O.M. Jensen, P. Lura, Techniques and materials for internal water curing of concrete, Materials and Structures 39(9) (2006) 817-825.

[6] S. Mönnig, P. Lura, Superabsorbent Polymers - An Additive to Increase the Freeze-Thaw Resistance of High Strength Concrete, in: C.U. Grosse (Ed.), Advances in Construction Materials 2007, Springer Berlin Heidelberg, Berlin, Heidelberg, 2007, pp. 351-358.

[7] S. Laustsen, M.T. Hasholt, O.M. Jensen, Void structure of concrete with superabsorbent polymers and its relation to frost resistance of concrete, Materials and Structures 48(1) (2015) 357-368.

[8] M. Tsuji, A. Okuyama, K. Enoki, S. Suksawang, Development of new concrete admixture preventing from leakage of water through cracks, JCA Proc. of Cement \& Concrete (Japan Cement Association) 52 (1998) 418-423.

[9] M. Tsuji, K. Shitama, D. Isobe, Basic studies on simplified curing technique, and prevention of initial cracking and leakage of water through cracks of concrete by applying superabsorbent polymers as new concrete admixture, Journal of the Society of Materials Science, Japan 48(11) (1999) 1308-1315.

[10] H. Lee, H. Wong, N. Buenfeld, Potential of superabsorbent polymer for self-sealing cracks in concrete, Advances in Applied Ceramics 109(5) (2010) 296-302. 
[11] H.X.D. Lee, H.S. Wong, N. Buenfeld, Self-sealing cement-based materials using superabsorbent polymers, International RILEM Conference on Use of Superabsorbent Polymers and Other New Additives in Concrete, Lyngby, 2010, pp. 171-178.

[12] H.X.D. Lee, Self-sealing of cracks in cement-based materials using superabsorbent polymers, Imperial College London, 2011.

[13] H.X.D. Lee, H.S. Wong, N.R. Buenfeld, Self-sealing of cracks in concrete using superabsorbent polymers, Cement and Concrete Research 79 (2016) 194-208.

[14] D. Snoeck, S. Steuperaert, K. Van Tittelboom, P. Dubruel, N. De Belie, Visualization of water penetration in cementitious materials with superabsorbent polymers by means of neutron radiography, Cement and Concrete Research 42(8) (2012) 1113-1121.

[15] D. Snoeck, K. Van Tittelboom, S. Steuperaert, P. Dubruel, N. De Belie, Self-healing cementitious materials by the combination of microfibres and superabsorbent polymers, Journal of Intelligent Material Systems and Structures 25(1) (2012) 13-24.

[16] V. Mechtcherine, H.-W. Reinhardt, Application of super absorbent polymers (SAP) in concrete construction: state-of-the-art report prepared by Technical Committee 225-SAP, Springer Science \& Business Media2012.

[17] T. Tanaka, D. Fillmore, S.-T. Sun, I. Nishio, G. Swislow, A. Shah, Phase transitions in ionic gels, Physical Review Letters 45(20) (1980) 1636.

[18] J. Ricka, T. Tanaka, Swelling of ionic gels: quantitative performance of the Donnan theory, Macromolecules 17(12) (1984) 2916-2921.

[19] H.H. Hooper, J.P. Baker, H.W. Blanch, J.M. Prausnitz, Swelling equilibria for positively ionized polyacrylamide hydrogels, Macromolecules 23(4) (1990) 1096-1104.

[20] U. Gedde, Polymer physics, Springer2013.

[21] H. Kang, J. Xie, Effect of concentration and $\mathrm{pH}$ of solutions on the absorbency of polyacrylate superabsorbents, Journal of Applied Polymer Science 88(2) (2003) 494-499.

[22] L.P. Esteves, Superabsorbent polymers: On their interaction with water and pore fluid, Cement and concrete composites 33(7) (2011) 717-724.

[23] C. Schröfl, V. Mechtcherine, M. Gorges, Relation between the molecular structure and the efficiency of superabsorbent polymers (SAP) as concrete admixture to mitigate autogenous shrinkage, Cement and Concrete Research 42(6) (2012) 865-873.

[24] Q. Zhu, C.W. Barney, K.A. Erk, Effect of ionic crosslinking on the swelling and mechanical response of model superabsorbent polymer hydrogels for internally cured concrete, Materials and Structures 48(7) (2015) 2261-2276.

[25] A. Mignon, G.-J. Graulus, D. Snoeck, J. Martins, N. De Belie, P. Dubruel, S. Van Vlierberghe, pHsensitive superabsorbent polymers: a potential candidate material for self-healing concrete, Journal of Materials Science 50(2) (2015) 970-979.

[26] V. Mechtcherine, E. Secrieru, C. Schröfl, Effect of superabsorbent polymers (SAPs) on rheological properties of fresh cement-based mortars - development of yield stress and plastic viscosity over time, Cement and Concrete Research 67 (2015) 52-65.

[27] C. Schroefl, V. Mechtcherine, P. Vontobel, J. Hovind, E. Lehmann, Sorption kinetics of superabsorbent polymers (SAPs) in fresh Portland cement-based pastes visualized and quantified by neutron radiography and correlated to the progress of cement hydration, Cement and Concrete Research 75(Supplement C) (2015) $1-13$.

[28] R. Bowen, Groundwater, Springer Science \& Business Media1986.

[29] E.M. Gartner, F.J. Tang, S.J. Weiss, Saturation factors for calcium hydroxide and calcium sulfates in fresh Portland cement pastes, Journal of the American Ceramic Society 68(12) (1985) 667-673. 
[30] W.F. Lee, R.J. Wu, Superabsorbent polymeric materials. I. Swelling behaviors of crosslinked poly (sodium acrylate - co - hydroxyethyl methacrylate) in aqueous salt solution, Journal of Applied Polymer Science 62(7) (1996) 1099-1114.

[31] NWSP 240.0.R2 (15) Polyacrylate Superabsorbent Powders - Determination of the Free Swell Capacity in Saline by Gravimetric Measurement, Nonwovens Standard Procedures, EDANA-INDA 2015, p. 9.

[32] H.X.D. Lee, H.S. Wong, N. Buenfeld, Estimating the swelling ratio of superabsorbent polymers in cement-based materials, RILEM International Conference, Use of superabsorbent polymers and other new additives in concrete, Lyngby, 2010, pp. 15-18.

[33] V. Howard, M. Reed, Unbiased stereology: three-dimensional measurement in microscopy, BIOS Scientific Publishers, Oxford, 2004.

[34] J.C. Russ, R.T. Dehoff, Practical stereology, Springer2012.

[35] H.S. Wong, N.R. Buenfeld, Patch microstructure in cement-based materials: Fact or artefact?, Cement and Concrete Research 36(5) (2006) 990-997.

[36] H.S. Wong, N.R. Buenfeld, Monte Carlo simulation of electron-solid interactions in cement-based materials, Cement and Concrete Research 36(6) (2006) 1076-1082.

[37] R. Schweins, K. Huber, Collapse of sodium polyacrylate chains in calcium salt solutions, The European Physical Journal E: Soft Matter and Biological Physics 5(1) (2001) 117-126.

[38] P.Y.B. Jar, Y.S. Wu, Effect of counter-ions on swelling and shrinkage of polyacrylamide-based ionic gels, Polymer 38(10) (1997) 2557-2560.

[39] W. Siriwatwechakul, J. Siramanont, W. Vichit-Vadakan, Behavior of Superabsorbent Polymers in Calcium- and Sodium-Rich Solutions, Journal of Materials in Civil Engineering 24(8) (2012) 976-980.

[40] K. Huber, Calcium-induced shrinking of polyacrylate chains in aqueous solution, The Journal of Physical Chemistry 97(38) (1993) 9825-9830.

[41] I. Sabbagh, M. Delsanti, P. Lesieur, Ionic distribution and polymer conformation, near phase separation, in sodium polyacrylate/divalent cations mixtures: small angle X-ray and neutron scattering, The European Physical Journal B-Condensed Matter and Complex Systems 12(2) (1999) 253-260.

[42] R. Schweins, P. Lindner, K. Huber, Calcium induced shrinking of NaPA chains: a SANS investigation of single chain behavior, Macromolecules 36(25) (2003) 9564-9573.

[43] F. Fantinel, J. Rieger, F. Molnar, P. Hübler, Complexation of polyacrylates by Ca2+ ions. Timeresolved studies using attenuated total reflectance Fourier transform infrared dialysis spectroscopy, Langmuir 20(7) (2004) 2539-2542.

[44] S. Laustsen, D.P. Bentz, M.T. Hasholt, O.M. Jensen, CT measurement of SAP voids in concrete, Use of superabsorbent polymers and other new additives in concrete, RILEM Proceedings PRO 74 (2010) 153-162.

[45] N. Nestle, A. Kühn, K. Friedemann, C. Horch, F. Stallmach, G. Herth, Water balance and pore structure development in cementitious materials in internal curing with modified superabsorbent polymer studied by NMR, Microporous and Mesoporous Materials 125(1) (2009) 51-57.

[46] P. Trtik, B. Muench, W. Weiss, G. Herth, A. Kaestner, E. Lehmann, P. Lura, Neutron tomography measurements of water release from superabsorbent polymers in cement paste, International RILEM conference on material science, RILEM Publications SARL, 2010, pp. 175-185.

[47] H.F. Taylor, A method for predicting alkali ion concentrations in cement pore solutions, Advances in Cement Research 1(1) (1987) 5-17.

[48] S.-Y. Hong, F. Glasser, Alkali binding in cement pastes: Part I. The CSH phase, Cement and Concrete Research 29(12) (1999) 1893-1903.

[49] H. Brouwers, R. vanEijk, Alkali concentrations of pore solution in hydrating OPC, Cement and Concrete Research 33(2) (2003) 191-196. 
Cement \& Concrete Composites (2018) Accepted for publication 